\title{
EXOTIC OPTIONS FOR INTERRUPTIBLE ELECTRICITY SUPPLY CONTRACTS
}

\author{
RAJNISH KAMAT and SHMUEL S. OREN \\ Department of Industrial Engineering and Operations Research, \\ University of California, Berkeley, California 94720 \\ kamat@ieor.berkeley.edu・oren@ieor.berkeley.edu
}

(Received February 2000; revisions received August 2000, February 2001; accepted May 2001)

\begin{abstract}
This paper presents the design and pricing of financial contracts for the supply and procurement of interruptible electricity service. While the contract forms and pricing methodology have broader applications, the focus of this work is on electricity market applications, which motivate the contract structures and price process assumptions. In particular, we propose a new contract form that bundles simple forwards with exotic call options that have two exercise points with different strike prices. Such options allow hedging and valuation of supply curtailment risk, while explicitly accounting for the notification lead time before curtailment.

The proposed instruments are priced under the traditional GBM price process assumption and under the more realistic assumption (for electricity markets) of a mean reverting price process with jumps. The latter results employ state-of-the-art Fourier transforms techniques.
\end{abstract}

$\mathrm{S}$ weeping changes in the electric power industry around the world over the last decade have been directed at increasing competition in the generation of electricity. This has been accompanied by a commoditization of electricity with the emergence of spot markets, along with forward and derivative markets. On the operations side, various forms of supply contracts serve purposes such as risk management and economic efficiency improvement through load management. Such contracts can be emulated and priced by means of financial instruments. Of particular interest are contracts that facilitate demand-side participation in the mitigation of supply shortages for energy and reserves. Newly deregulated electricity markets have shown very little demand elasticity. Price spikes have reached $\$ 7,000-\$ 10,000$ per MWh compared to normal prices of around $\$ 25$ per MWh. This has brought the need for demand responsiveness to the forefront to make these markets workable. Failures of markets for reserves (that are needed to ensure system reliability) in California, New England, and New York have also been largely attributed to the lack of demand-side response and spurred renewed interest in "load as a resource."

Two key elements that are needed to enable demand side participation in the mitigation of price spikes and provision of reserves are the metering and control technology that will make such response possible, and appropriate contractual arrangements that will provide appropriate incentives to loads to subject themselves to curtailment. While load curtailment can provide an efficient substitute for generation capacity in providing balancing energy and reserves, it is erroneous to treat load and generation resources as interchangeable in terms of market design and participation incentives. The flexibility and response capability of both generation and load resources are predicated on metering and control technology. However, while generation resources are physically constrained by their ramping capability, given proper communication and control, the responsiveness of load resources is cost driven. Load can respond instantly to a contingency by the flip of a switch, but the cost of such a response may be high. Different load types have different costs associated with notification time and duration of an interruption. For example, heating and cooling applications with some form of storage can provide quick response but would be more sensitive to duration, while manufacturing-type load would be sensitive to notification time but less sensitive to duration of a curtailment. Hence, proper design of contracts that enable loads to hedge their specific risk associated with service interruptions is essential in recruiting a portfolio of demand-side resources that will meet the requirements for responsiveness and economic efficiency to make load a viable resource.

This paper focuses on the pricing of three interruptible supply contracts emulated using forwards and options. In particular, we propose a new contract form that bundles a simple forward contract with an exotic call option that has two exercise points with different strike prices. Such options allow hedging and valuation of supply curtailment risk while explicitly accounting for the notification lead time before curtailment. Our analysis can also be considered as a starting point for analyzing more complex contracts with multiple strike points.

We model the behavior of electricity spot prices using three single-factor stochastic processes that have been widely used in the asset pricing and commodity pricing literatures. First, the canonical geometric Brownian motion (GBM) model is considered for illustrative purposes and to link our study to past literature in the area (see Gedra 1991, 
Gedra and Varaiya 1993, and Oren 1999). In this model the spot commodity is viewed as a tradable security. This is clearly inappropriate for electricity, which is essentially nonstorable (even in markets where there is a large amount of hydrogeneration only water, i.e., the fuel, can be stored and not the final product, i.e., electricity. Hence, such storage will not mitigate temporal shortages of generation capacity.). Also, the volatility of future spot prices in this model increases without bound while there is evidence that commodity prices, and more specifically electricity prices, exhibit mean reversion (see Kaminsky 1997). Second, we consider a model where the logarithm of electricity spot price follows a mean-reverting process of the Ornstein-Uhlenbeck type, also known as an affine diffusion (AD). This model has been used in modeling commodity prices (see Bjerksund and Ekern 1995, Ross 1995, and Schwartz 1997). In this case, the spot price, or equivalently its logarithm, is not an asset in the usual sense but is viewed as an underlying state variable upon which contingent claims can be written. Gibson and Schwartz (1990) and Miltersen and Schwartz (1998) have also proposed multifactor extensions of this model in the literature. These introduce stochastic convenience yield as an additional factor in the model. Convenience yield is defined as the benefit from holding inventory of the commodity and is not easily justified in electricity markets, as electricity is almost nonstorable. Schwartz and Smith (2000) provide an alternative model with two state variables, modeling mean reversion in short-term prices and uncertainty in the equilibrium level to which prices revert respectively, which is equivalent to the model with convenience yield. Finally, we consider a mean-reverting jump-diffusion model, which falls in the class of affine jump diffusions (AJDs). Merton (1976) introduced single-factor jump-diffusion models in his seminal work. The jump part of the model is usually modeled using a Poisson-driven process. More recently, Hilliard and Reis (1998) have used multifactor AJD models, introduced in Duffie and Kan (1996), for describing commodity prices. Deng (1999) was the first to use multifactor AJD models to describe electricity spot prices (also, see Birge and Kou 1999 for a single-factor specification). Deng presents several specifications, one having regime switching and one with a second factor to incorporate stochastic volatility. The introduction of jumps in electricity spot prices captures abrupt changes in the market caused by unpredictable events such as outages and is consistent with near nonstorability. This, however, leads to incomplete markets. As our interest is in the pricing of contingent claims on the state process, we work directly under an equivalent martingale measure. Duffie et al. (1998) point out that the existence of some equivalent martingale measure and the absence of arbitrage are essentially equivalent properties even when markets are incomplete (also, see Harrison and Kreps 1979). We do not address estimation or calibration of the models but note that the behavior of prices can also be modeled under the "original" or "data-generating" measure. Reasonable assumptions about the functional form of the state-price density (also known as the "pricing kernel" or the "marginal-rateof-substitution process") lead to our model under an equivalent martingale measure (Duffie et al. 1998).

While various authors have considered the pricing of forward contracts and simple options, we present new pricing formulae for the exotic option embedded in one of our contracts. We use transform analysis developed in a series of papers by Stein and Stein (1991), Heston (1993), and others and generalized in Duffie et al. (1998) to price the contracts under the affine jump diffusion (see Deng 1999 for an application to electricity derivatives). We extend Duffie et al.'s methodology of calculating transforms for simple options to the case where the option can be exercised at two time points and use a multivariate inversion technique developed in Shepard (1991) to arrive at almost closed-form solutions for the exotic option in our analysis. We leave extensions to regime switching, which accurately describes spikes in electricity prices, and stochastic volatility, which can be attributed to unpredictable demand and weather patterns, to future research.

An alternative methodology to model commodity prices relies on the forward curve as input to the model. Heath et al. (1992) first suggested this approach for modeling interest-rate-based securities. Amin et al. (1995) develop similar models for the term structure of energy futures prices. Deng et al. (1998) use a third approach of modeling futures prices directly.

Thompson (1995) presents a framework to analyze pathdependent claims of the kind analyzed in this paper. Thompson considers take-or-pay contracts where the takeor-pay level is enforced over a period of time covering a multiple number of exercise points, with or without a makeup clause over a number of such periods. Using latticebased methodology he shows that for contracts without a make-up clause, an analytical formula can be derived that can be used to calculate the optimal amount to exercise at each point. If a make-up clause is included this analytical form is not the most practical form for calculation, and he suggests using a grid search to determine the optimal amount. This methodology is especially useful when the price process follows geometric Brownian motion. Our approach can be seen as an alternative to lattice-based methods when there are a few exercise points in a jumpdiffusion setting where the simplicity of the lattice-based methods is lost.

The remainder of the article is organized as follows. We describe the design of the contracts using standard financial instruments in $\S 1$. In $\S 2$, we present pricing formulae for the GBM and AD processes. We discuss the AJD model and introduce transform analysis used for pricing contracts under this model in $\S 3$. In $\$ 4$, we conclude and discuss some possible extensions of our work. All the proofs are collected in an appendix.

\section{CONTRACT DESIGN}

Interruptible or curtailable service contracts aim to supply electricity at reduced cost by taking advantage of customers' flexibility to manage their load. Many utilities 
have introduced such contracts in the past as part of various demand-side management programs. Such contracts allow suppliers to provide electricity to those customers who are willing to pay the highest prices in times of scarcity and give customers lower rates. Chao and Wilson (1987) first studied the implementation of such contracts as priority service. If the time of notification of curtailment is only a few minutes before delivery, the supplier can substitute these demand-side measures for reserve capacity that it must have on hand for reliable operation of the grid. This reduces cost of operation and the need for expansion of capacity. While a shorter warning time gives a supplier the flexibility it needs to reduce costs, from the customer's point of view earlier notification of an impending curtailment may be crucial in mitigating the shortage cost of an interruption (for example, by closing operation). A similar situation may exist with respect to long-term supply contracts. Strauss and Oren (1993) describe a methodology for the design of priority service price schedules with such an early notification option. Another type of interruptible service is one where the option of curtailment is with the customer. Such contracts exist between load-serving entities (LSE) and independent power producers (IPP), where the LSE purchases electricity from the IPP only if the contracted price is below its marginal cost (or the spot price if a spot market exists).

With deregulation of the electric power industry in the United States and around the world, quantity controls such as curtailments are being replaced by price signals provided by daily and hourly spot markets for electricity that have been established as part of the industry restructuring. In such markets, a customer can benefit from its flexibility by responding to the price signal and exercising its "real option" to reduce consumption when the spot price is high. Such an approach requires that the customer actively participate in the spot market. Customers that prefer to avoid the risk of price fluctuation can "hedge" the price risk by entering into forward commitments. A forward contract guarantees a fixed price for power regardless of the spot price (these can also be implemented as contracts for difference, where any differences in the spot price from the forward price are settled ex post). Simple hedges, however, do not account for a customer's flexibility and willingness to curtail its load when the spot price is high because of shortages or high demand. Customers with such flexibility could exercise their curtailment option and sell back their forward-acquired power during periods of high spot prices. Alternatively, these customers could sell their option to their electricity supplier in exchange for a fixed rebate on the forward price. A call (put) option gives its holder the right but not the obligation to buy (sell) electricity at a predetermined "strike" price. The call (put) option will be exercised only when the spot price is higher (lower) than the strike price. Holding portfolios of these basic securities can simulate more complex payoff structures. The rebate or interruptible rate discount would equal the actuarial value of the option. Different load types have different costs associated with notification time and duration of an interruption. For a particular load type, if interruption costs change significantly as time approaches time of delivery, this calls for contracts with multiple points at which the outlook for the delivery period is evaluated and supply decisions are made. We consider the three interruptible supply contracts described above in our analysis. All of the contracts have one feature in common-they involve forward contracting with some optionality built into the forward contract. We now describe the replication of these contracts with forwards and options in greater detail.

\subsection{Interruptible Supply Contract or "Callable Forward"}

Gedra (1991) and Gedra and Varaiya (1993) introduce "callable forwards" as potential substitutes for interruptible service contracts and provide a thorough analysis of their efficiency properties. In a "callable forward," the customer is "long" one forward contract and "short" one call option, which has a customer-selected strike price. The supplier holds opposite positions and can exercise the call option whenever the spot price exceeds the strike price, effectively canceling the forward contract at the time of delivery. The discount that the customer gets on the forward price is the option price at the time of contracting, continuously compounded to the delivery date (see Figure 1 for a timeline of this contract).

\subsection{Dispatchable Independent Power Producer Contract or "Putable Forward"}

Gedra (1991) and Gedra and Varaiya (1993) also propose "putable forwards" to emulate dispatchable independent power producer (IPP) supply contracts. In a "putable forward" the customer is "long" one forward contract and "long" one put option, which has a supplier-selected strike price, while the supplier holds opposite positions. The customer can exercise the put option whenever the spot price is below the strike price, effectively canceling the forward contract at the time of delivery. In this case, the premium that the customer pays on the forward price is the option price at the time of contracting, continuously compounded to the delivery date.

Figure 1. Timeline for the contract.

\begin{tabular}{l}
$\begin{array}{l}\text { Time of } \\
\text { Contracting }\end{array}$ \\
\hline $\mathrm{T}$
\end{tabular}




\subsection{Interruptible Supply Contract with Early Notification}

One shortcoming of the "callable forward" is that a customer with high interruption cost, e.g., an industrial customer, may not provide a viable strike price for the contract. On the other hand, including another earlier date, perhaps even a few months before delivery will provide incentive for such firms to plan shutdowns in a period of forecasted scarcity. This could be the case when there is a weak rainy season for a hydrodominated grid or planned shutdowns of some major electricity plants. We will call this contract an interruptible service contract with early notification (see Strauss and Oren 1993 and Oren 1999).

To understand the efficiency properties of such a contract let us assume that a customer has a shortage cost $\$ V_{T_{2}}$ per MWh if curtailed close to delivery, but a lower shortage cost of $\$ V_{T_{1}}$ per MWh if notified of curtailment at an earlier time, $T_{1}$. Efficiency dictates that this customer should be curtailed at time $T_{2}$ only if the spot price is above its reservation price of $V_{T_{2}}$ (and if curtailment has not occurred earlier). We can also evaluate the efficient decision at $T_{1}$ by looking at the two alternatives available at $T_{1}$. We can either notify the customer of curtailment at $T_{2}$, essentially killing the time- $T_{2}$ option of curtailing just before delivery, or wait until $T_{2}$ and retain the option. In this case, the efficient decision is to notify that curtailment will occur at $T_{2}$ only if the forward price at $T_{1}$ is greater than the shortage cost at $T_{1}$ plus the option value of time- $T_{2}$ curtailment.

This efficient outcome can be replicated by a double call option with two strike prices specified by the customer, $k_{T_{1}}$ and $k_{T_{2}}$, for times $T_{1}$ and $T_{2}$, respectively. Oren (1999) shows that the strike prices specified by a rational customer will be its reservation prices (from shortage costs) and the instrument will be able to replicate an efficient outcome that would reflect decisions taken by a benevolent central planner with perfect information about shortage costs. The discount that the customer gets on the forward price is the price of this double call option at the time of contracting, continuously compounded to the date of delivery. In order to price the double call, we begin by analyzing its payoff at time $T_{1}$. If the double call is exercised at $T_{1}$ the supplier is free to enter into a new forward contract, which yields a payoff of $f_{T_{1}}-k_{T_{1}}$ at $T_{2}\left(k_{T_{1}}\right.$ is the maximum forward price the current customer would contract for at $T_{1}$ for delivery at $T_{2}$ ). Exercising the option at $T_{1}$, however, means that the time- $T_{2}$ option embedded in it is killed. Therefore, the optimal exercise policy is to exercise only if $f_{T_{1}}>\bar{k}$, where $e^{-r\left(T_{2}-T_{1}\right)}\left(\bar{k}-k_{T_{1}}\right)=C_{T_{1}}\left(k_{T_{2}} \mid \bar{k}\right)$, the value of the time- $T_{2}$ curtailment option. The forward price $\bar{k}$ is the effective strike price at which the double call is exercised at $T_{1}$. If the double call is not exercised at $T_{1}$, its value after that time is equal to that of a simple call option with strike price $k_{T_{2}}$ expiring at $T_{2}$. This call will be exercised only if the spot price at $T_{2}$ is greater than the strike price. Therefore, the double call is able to replicate the efficient decisions mentioned above.
Figure 2. Analyzing the payoff of the double call option at time $T_{1}$.

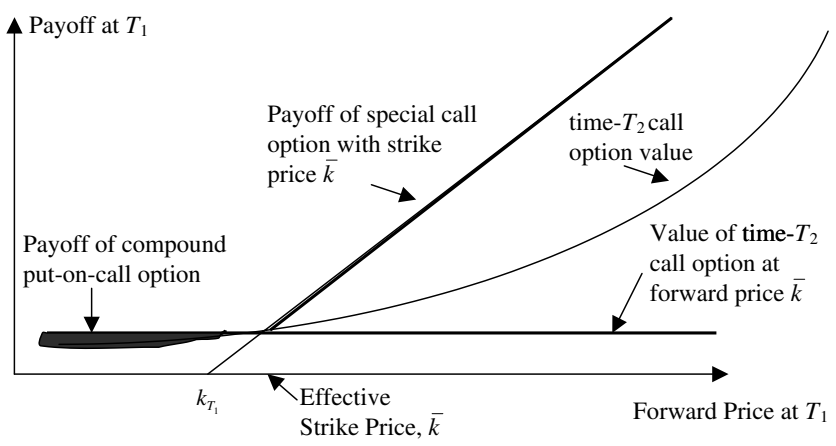

We now proceed by breaking up the payoff of the double call at $T_{1}$ into payoffs of three simpler derivatives-a special call option expiring at $T_{1}$ with strike price $\bar{k}$ (actual payoff does not occur until $T_{2}$ and the slope of the effective payoff at $T_{1}$ is not equal to 1 ), plus the value of the time- $T_{2}$ call option given that the forward price is $\bar{k}$, less the price of a compound put option (with the time- $T_{2}$ call option as underlying) with strike price $e^{-r\left(T_{2}-T_{1}\right)}\left(\bar{k}-k_{T_{1}}\right)$. The price of the call option at time $t$ (before time $T_{1}$ ) can therefore be written as (see Figure 2)

$$
\begin{aligned}
\widehat{C}_{t}\left(k_{T_{1}}, k_{T_{2}} \mid f_{t}\right)= & C_{t, T_{1}}^{\prime}\left(\bar{k} \mid f_{t}\right)+e^{-r\left(T_{1}-t\right)} C_{T_{1}}\left(k_{T_{2}} \mid f_{T_{1}}=\bar{k}\right) \\
& -P_{t, T_{1}}^{c o}\left(e^{-r\left(T_{2}-T_{1}\right)}\left(\bar{k}-k_{T_{1}}\right) \mid f_{t}\right),
\end{aligned}
$$

where the first term is the value of a special call option expiring at $T_{1}$ with strike price $\bar{k}$. The second term is the discounted sure value of the time- $T_{2}$ call option at a time- $T_{1}$ forward price of $\bar{k}$. The third term is the price of a compound put-on-call option that allows the holder to sell, at time $T_{1}$, the time- $T_{2}$ call option at a strike price of $e^{-r\left(T_{2}-T_{1}\right)}\left(\bar{k}-k_{T_{1}}\right)$.

\section{GEOMETRIC BROWNIAN MOTION AND AFFINE DIFFUSION}

The proliferation of financial derivatives has led to many developments in techniques for modeling these instruments (see Cox and Rubinstein 1985, Hull 2000). The literature dealing specifically with financial modeling in electricity markets, however, is more recent (see Cater 1995, Kaminsky 1997, Pilipovic 1998, Oren 1999, and Deng 1999). Oren uses geometric Brownian motion GBM to describe the electricity spot price process and derives prices of the three contracts under this canonical form. This section first revisits the pricing problem under GBM and provides a simpler formula for the double call option than the one derived in Oren. As noted above, in this model the spot commodity is viewed as a tradable security, which is clearly inappropriate for electricity. Also, the volatility of future spot prices increases without bound. It has been observed, however, that electricity prices exhibit mean reversion due to production characteristics and seasonal effects (see Kaminsky 1997). The GBM assumption will 
therefore produce systematically erroneous results when used for pricing electricity contracts and derivatives. However, as we will see below, these results are useful in the sense that they can be easily extended to the more realistic mean-reverting price process. For the mean-reverting case we then consider a model where the logarithm of the spot price follows a mean-reverting process of the OrnsteinUhlenbeck type also known as an affine diffusion (AD). In this case, the spot price, or equivalently its logarithm, is not an asset in the usual sense but is viewed as an underlying state variable upon which contingent claims can be written.

We make the following assumptions throughout our analysis:

Assumption 1. The interest rate, $r$, is a constant.

Assumption 2. The volatility parameter, $\sigma$, is a constant.

Also, Let $E^{Q}\left[\cdot \mid F_{t}\right]$ denote the expectation under the measure $Q$ conditional on information at time $t, F_{t}$.

\subsection{Geometric Brownian Motion}

Under geometric Brownian motion the spot price process follows:

$\frac{d S_{t}}{S_{t}}=\mu_{t} d t+\sigma d B_{t}$,

where $S_{t}$ is the spot price, $\mu_{t}$ and $\sigma$ are drift and volatility parameters, respectively, and $B_{t}$ is standard Brownian motion. It can be shown by an application of Girsanov's theorem (see Oksendal 1995) that under the equivalent martingale measure or the risk-neutral measure (see Harrison and Kreps 1979), the process will follow:

$\frac{d S_{t}}{S_{t}}=r d t+\sigma d B_{t}^{Q}$,

where $B_{t}^{Q}$ is Brownian motion under the risk-neutral measure and $r$ is the interest rate. We can write down the process for $\ln S_{t}$ under the equivalent martingale measure by applying Itô's lemma to (3) (see Oksendal 1995). Observe that given $S_{t}, \ln S_{T}$ will be normally distributed.

$d \ln S_{t}=\left(r-\frac{1}{2} \sigma^{2}\right) d t+\sigma d B_{t}^{Q}$.

The above implies that $\ln \frac{S_{T}}{S_{t}} \sim N\left(\left(r-\frac{1}{2} \sigma^{2}\right)(T-t)\right.$, $\left.\sigma^{2}(T-t)\right)$ and thus the spot price is lognormal at time $\mathrm{T}$. This is the usual Brownian motion model used to model stock prices.

2.1.1. Forward Prices. Consider a forward contract for delivery at time $T_{2}$. The forward price of an underlying at the time of contracting, $t$, is defined as the price paid at delivery that sets the price of a derivative with the payoff $S_{T_{2}}-f_{t}$ to zero. As the values of all derivative securities are martingales (after discounting) under the risk-neutral measure (see Harrison and Kreps 1979, Duffie 1996), the forward price can be expressed as

$f_{t}=E^{Q}\left[S_{T_{2}} \mid F_{t}\right]=E^{Q}\left[\exp \left\{\ln S_{T_{2}}\right\} \mid F_{t}\right]$.
Because the forward price is an expectation of a time$T_{2}$ random variable, it will be a martingale under the riskneutral measure before time $T_{2}$. We can write down the process followed by $f_{t}$ using Itô's lemma on (3):

$d f_{t}=\sigma f_{t} d B_{t}^{Q}$

$\therefore f_{T_{2}}=f_{t} \exp \left\{-\frac{1}{2} \sigma^{2}\left(T_{2}-t\right)+\sigma\left(B_{T_{2}}^{Q}-B_{t}^{Q}\right)\right\}$.

Forward prices are also lognormal under this model and will converge to the spot price at the time of expiration, $T_{2}$.

2.1.2. Option Pricing. As described before, a call option expiring at time $T_{2}$ on a forward contract for delivery at the same time is a security with a payoff of $\left(f_{T_{2}}-k_{T_{2}}\right)^{+}$, where $f_{T_{2}}$ is the price of the underlying at the time of expiration, $k_{T_{2}}$ is the strike price and the notation $(x)^{+}=\max (x, 0)$. Using the valuation principle described above, the call option can be valued as

$C_{t}\left(k_{T_{2}} \mid f_{t}\right)=E^{Q}\left[e^{-r\left(T_{2}-t\right)}\left(f_{T_{2}}-k_{T_{2}}\right)^{+} \mid F_{t}\right]$.

Evaluating the above expectation using (6) for the forward price at $T_{2}$, one can derive a formula for the option price (see Figure 3 for a plot of the time- $T_{2}$ option prices at various time points before expiration). This formula is also known as Black's formula (see Black 1976).

Proposition 1. The option value in a "callable forward with early notification" after time $T_{1}$ is the price of a simple call option on the forward. The discount on the forward price in a "callable forward" is $e^{r t_{2}}$ times the option price given by

$C_{t}\left(k_{T_{2}} \mid f_{t}\right)=e^{-r t_{2}}\left[f_{t} N\left(d_{1}\right)-k_{T_{2}} N\left(d_{2}\right)\right]$,

where $f_{t}$ is the forward price at time $t$, and $k_{T_{2}}$ is the strike price of the option;

$d_{1}=\frac{\ln \left(f_{t} / k_{T_{2}}\right)+\frac{1}{2} \sigma^{2}\left(G B M, t, T_{2}\right)}{\sigma\left(G B M, t, T_{2}\right)} ;$

$d_{2}=d_{1}-\sigma\left(G B M, t, T_{2}\right)$;

$t_{2}=T_{2}-t$ and $\sigma^{2}\left(G B M, t_{1}, t_{2}\right)=\sigma^{2} .\left(t_{2}-t_{1}\right)$ for two time points $t_{1}, t_{2}$ and $t_{2}>t_{1}$. The premium on the forward price

Figure 3. Value of the time- $T_{2}$ call option under GBM $\left(t_{3}=T_{2}-T_{1}\right)$.

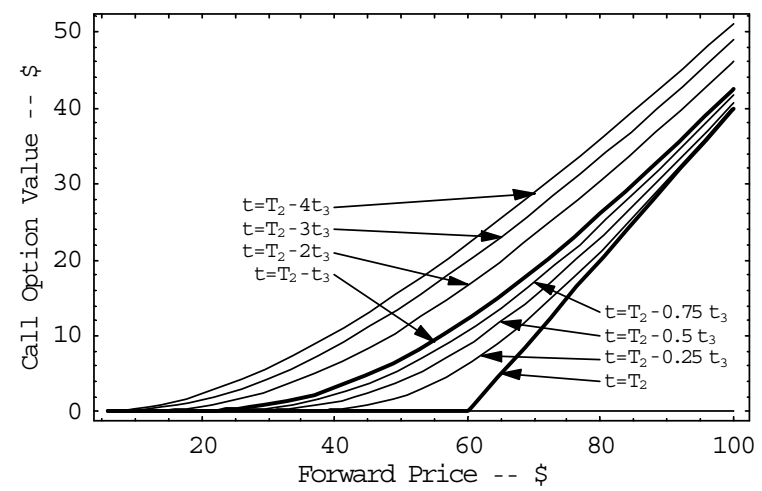


Figure 4. Optimal exercise policy for the double call option.

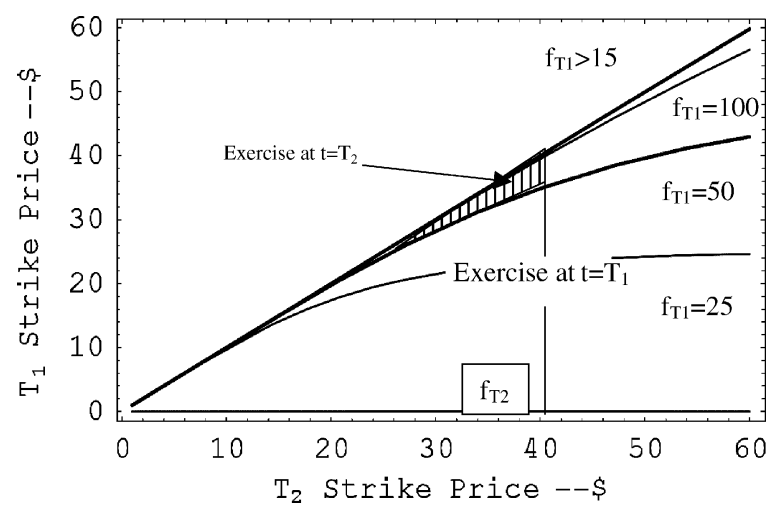

in a "putable forward" is $e^{r t_{2}}$ times the price of a put option given by

$P_{t}\left(k_{T_{2}} \mid f_{t}\right)=e^{-r t_{2}}\left[f_{t} N\left(-d_{1}\right)-k_{T_{2}} N\left(-d_{2}\right)\right]$.

Proof. See Appendix or Black (1976) for an alternative derivation.

2.1.3. The Callable Forward with Early Notification. In the previous section we show that the holder of a double call option will exercise it at time $T_{1}$ only if the forward price is above the effective strike price $\bar{k}$ (see $\S 1.3$ ). If early exercise is not optimal, the holder will exercise the option at $T_{2}$ only if the spot price is above the $T_{2}$ strike price. Figure 4 shows an example of this optimal exercise policy when the forward price at $T_{1}$ is $\$ 50$ and the spot price at $T_{2}$ is $\$ 40$. The double call option will be exercised at $T_{1}$ if the $T_{1}$ strike price is below the indifference curve corresponding to $f_{T_{1}}=\$ 50$. Additionally, if the $T_{1}$ strike price is above this curve, but the $T_{2}$ strike price is below the $T_{2}$ spot price of $\$ 40$ (shaded area in the plot), the option will be exercised at $T_{2}$.

To price the double call option before time $T_{1}$ we had broken down the option payoff at $T_{1}$ into three simpler derivatives (see Equation (1)). We can use the results in Proposition 1 to price the first two terms. The third term is a compound put-on-call option with a payoff of $\left[e^{-r\left(T_{2}-T_{1}\right)}\left(\bar{k}-k_{T_{1}}\right)-C_{T_{1}}\left(k_{T_{2}} \mid f_{T_{1}}\right)\right]^{+}$at time $T_{1}$. We use results in Geske (1979) adjusted for the fact that the underlying is an option on a forward contract to price this term. This leads to Proposition 2 (see Figure 5 for a plot of the values of the double call option under GBM at various time-points).

Proposition 2. The discount on the forward price is $e^{r t_{2}}$ times the price of the double call option:

$$
\begin{aligned}
\widehat{C}_{t}\left(k_{T_{1}},\right. & \left.k_{T_{2}} \mid f_{t}\right) \\
= & e^{-r t_{2}}\left[f_{t} N\left(d_{3}\right)-\bar{k} N\left(d_{4}\right)\right] \\
& +e^{-r t_{2}}\left[\bar{k} N\left(\bar{d}_{1}\right)-k_{T_{2}} N\left(\bar{d}_{2}\right)\right]-P_{t, T_{1}}^{c o}\left(k_{1} \mid f_{t}\right),
\end{aligned}
$$

Figure 5. Value of the double call option under GBM $\left(t_{3}=T_{2}-T_{1}\right)$.

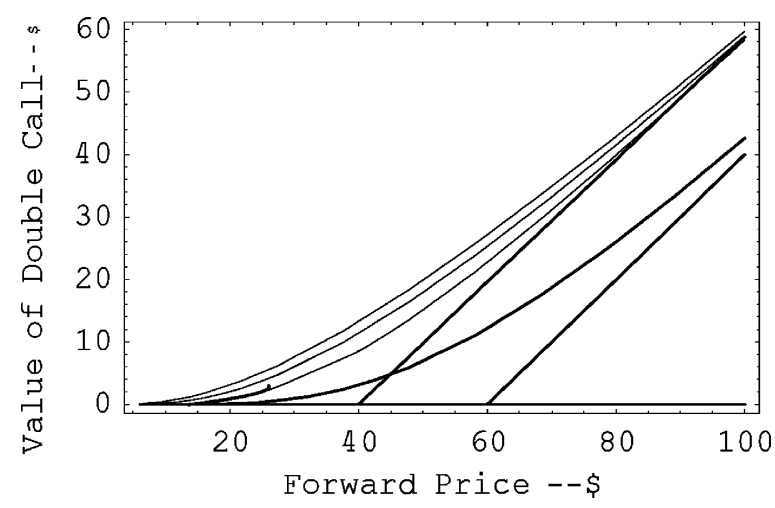

where $f_{t}$ is the forward price at time $t . t_{1}=T_{1}-t, t_{2}=$ $T_{2}-t, t_{3}=T_{2}-T_{1}$ and

$\bar{d}_{1}=\frac{\ln \left(\bar{k} / k_{T_{2}}\right)+\frac{1}{2} \sigma^{2}\left(G B M, T_{1}, T_{2}\right)}{\sigma\left(G B M, T_{1}, T_{2}\right)} ;$

$\bar{d}_{2}=\bar{d}_{1}-\sigma\left(G B M, T_{1}, T_{2}\right)$;

$d_{3}=\frac{\ln \left(f_{t} / \bar{k}\right)+\frac{1}{2} \sigma^{2}\left(G B M, t, T_{1}\right)}{\sigma\left(G B M, t, T_{1}\right)} ;$

$d_{4}=d_{3}-\sigma\left(G B M, t, T_{1}\right)$

$$
\begin{aligned}
P_{t, T_{1}}^{c o}\left(k_{1} \mid f_{t}\right)= & e^{-r t_{2}} k_{T_{2}} N_{2}\left(-a_{2}, b_{2} ;-\sqrt{\frac{t_{1}}{t_{2}}}\right) \\
& -e^{-r t_{2}} f_{t} N_{2}\left(-a_{1}, b_{1} ;-\sqrt{\frac{t_{1}}{t_{2}}}\right) \\
& +e^{-r t_{1}} k_{1} N\left(-a_{2}\right),
\end{aligned}
$$

where $k_{1}=e^{-r t_{3}}\left(\bar{k}-k_{T_{1}}\right), N_{2}(a, b ; \rho)$ is the bivariate normal distribution with correlation $\rho$, and

$a_{1}=\frac{\ln \left(f_{t} / \bar{k}\right)+\frac{1}{2} \sigma^{2}\left(G B M, t, T_{1}\right)}{\sigma\left(G B M, t, T_{1}\right)} ;$

$b_{1}=\frac{\ln \left(f_{t} / k_{T_{2}}\right)+\frac{1}{2} \sigma^{2}\left(G B M, t, T_{2}\right)}{\sigma\left(G B M, t, T_{2}\right)} \quad$ and $\rho=-\sqrt{\frac{t_{1}}{t_{2}}}$;

$a_{2}=a_{1}-\sigma\left(G B M, t, T_{1}\right)$ and $b_{2}=b_{1}-\sigma\left(G B M, t, T_{2}\right)$.

Proof. See Appendix.

\subsection{Affine Diffusion (Mean Reverting)}

We now assume that the spot price follows the stochastic process:

$\frac{d S_{t}}{S_{t}}=\kappa\left(\mu-\ln S_{t}\right)+\sigma d B_{t}$,

where $\kappa>0$ is the magnitude of the speed of adjustment to the long-run mean log price, $\mu$, and $B_{t}$ is standard Brownian motion. For tractability, we make the assumption that $\mu$ is constant. Ideally, one could model seasonality through this parameter by using a seasonally adjusted 
long-run mean. Using similar steps as before one can show that the process followed by the log spot price under the risk-neutral measure is

$d X_{t}=\kappa\left(\theta-X_{t}\right) d t+\sigma d B_{t}^{Q}$,

where $X_{T}=\ln S_{t}$ and $\theta$ is the risk-adjusted long-run mean.

Incorporating mean reversion in the spot price process results in time-dependent volatility of the forward price. Spot and forward prices remain lognormal in this case with different volatility than the GBM case (see the proof of Proposition 3 in the appendix for details). As the forward price will converge in value and variance to the spot price at the delivery date, pricing formulae under an affine diffusion will have the same form as the GBM case with a different variance term. This leads to Proposition 3.

Proposition 3. Option prices, and hence discounts in the forward contracts under an affine diffusion, will have the same form as the GBM case with the variance term replaced by

$\sigma^{2}\left(M R, t_{1}, t_{2}\right)=\frac{\sigma^{2}}{2 \kappa}\left[1-\exp \left\{-2 \kappa\left(t_{2}-t_{1}\right)\right\}\right]$.

Proof. See Appendix.

Figure 6 shows the value of the time- $T_{2}$ call option under a mean-reverting spot price. Because information about mean reversion is included in the forward price, the only noticeable difference between option prices under GBM and the affine diffusion is the lack of time value in the affine diffusion case for longer time periods before expiration, i.e., the value converges rapidly to a steady state. Figure 7 is a plot showing the value of the double call option for various time points before the early exercise date.

\section{AFFINE JUMP-DIFFUSION}

This section extends the models in the previous section to include jump behavior in the price process. Nonstorability of electricity causes steep changes in prices with changing supply and demand conditions, which can be modeled as jumps in the price process. We use a class of processes

Figure 6. Value of the time- $T_{2}$ call option under an affine diffusion $\left(t_{3}=T_{2}-T_{1}\right)$.

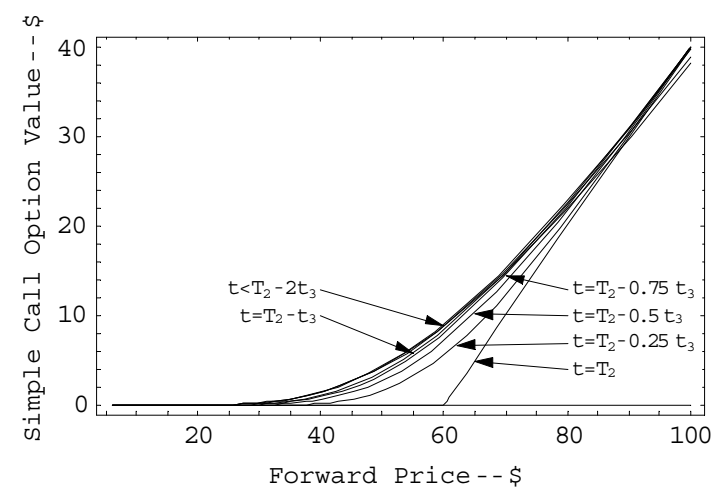

Figure 7. Value of the double call option under an affine diffusion $\left(t_{3}=T_{2}-T_{1}\right)$.

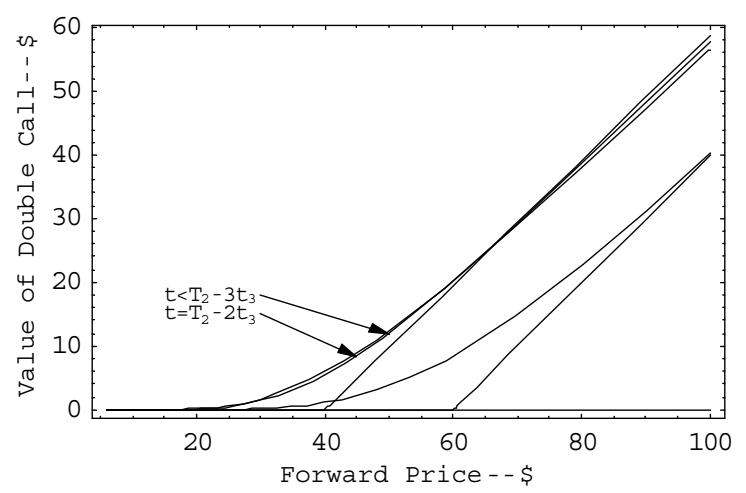

called affine jump-diffusions (AJDs), which incorporate many characteristics useful for modeling electricity spot prices (see the Appendix for a brief introduction to AJDs). Various aspects of the price process such as mean reversion, stochastic volatility, and jumps can be modeled using this class of processes. An advantage in calculating option prices using AJDs is that the Fourier transform of the distribution of the underlying is known-for some cases up to the solution of ODEs (see Duffie et al. 1998). This provides almost closed-form option pricing formulae in terms of the inverse of the transforms rather than in the form of infinite sums as have been derived in the past (see Merton 1976, Bates 1991, and Hilliard and Reis 1998). Because our interest is in the pricing of contingent claims on the underlying state process, we work directly under an equivalent martingale measure. Under this measure, we assume that the logarithm of the spot price will follow the stochastic process:

$d X_{t}=\kappa\left(\theta-X_{t}\right) d t+\sigma d B_{t}^{Q}+\sum_{i=1}^{2} d Z_{t}^{i}$,

where $X_{t}=\ln S_{t} ; \kappa, \theta$, and $\sigma$ are parameters; $B_{t}^{Q}$ is standard Brownian motion under the equivalent martingale measure; $Q$, and $Z^{i}$ s are independent compound Poisson processes under $Q$, with arrival intensities, $\lambda_{i}$ and exponential jump-sizes with transforms, $\phi_{i}(c, t)=\frac{1}{1-\mu_{i} c}$ for $i=1,2$ $\left(\phi_{i}(c, t)=E\left[e^{c x}\right]\right.$, where $x$ is the jump size and $c$ is a complex parameter). We use two Poisson processes with positive and negative expected jump values and different intensities to model unexpected increase and decrease in prices, respectively. The choice of the number of jumps to be included in the model will mainly be decided by the need for parsimony in the number of parameters to be estimated.

\subsection{Transforms and Forward Prices}

Define the transform of $X_{T_{2}}$ :

$\Psi\left(v, t, T_{2}, X_{t}\right)=E^{Q}\left[e^{-r\left(T_{2}-t\right)} \exp \left\{v X_{T_{2}}\right\} \mid F_{t}\right]$. 
Except for the discounting, this is the characteristic function of the distribution of $X_{T_{2}}$. As $\Psi$ is the expected discounted payoff of a single random variable, $\Psi e^{-r t}$ will be a martingale under $Q$ (some regularity conditions are required; see Duffie et al. 1998). Following Duffie et al. it is conjectured that the transform will have an exponential affine form (see the Appendix for some justification of this functional form):

$$
\begin{aligned}
& \Psi\left(v, t, T_{2}, X_{t}\right) \\
& \quad=\exp \left[\alpha^{\prime}\left(\left(T_{2}-t\right), v\right)+\beta^{\prime}\left(\left(T_{2}-t\right), v\right) X_{t}\right] .
\end{aligned}
$$

Because special cases of this process are Gaussian, the exponential affine form is a natural choice. It can be shown, by applying Itô's lemma, that the transform takes this form for the one time-point case, where $\alpha^{\prime}$ and $\beta^{\prime}$ solve the following ODEs (see the Appendix for a derivation. Duffie et al. 1998 derive these ODEs for a multifactor model):

$$
\begin{array}{ll}
\frac{d}{d t} \beta^{\prime}(t, v)+B\left(\beta^{\prime}(t, v), t\right)=0 & \beta^{\prime}(0, v)=v, \\
\frac{d}{d t} \alpha^{\prime}(t, v)+A\left(\beta^{\prime}(t, v), t\right)=0 & \alpha^{\prime}(0, v)=0,
\end{array}
$$

where for complex c,

$B(c, t)=-\kappa c$,

$A(c, t)=\kappa \theta c+\frac{1}{2} \sigma c^{2}-r+\sum \lambda_{j}\left(\phi_{j}(c, t)-1\right)$.

We can integrate the differential equations to get

$$
\begin{aligned}
\beta^{\prime}(t, v)= & \nu e^{-\kappa \theta t}, \\
\alpha^{\prime}(t, v)= & \theta \nu\left(1-e^{-\kappa \theta t}\right)+\frac{\sigma^{2} \nu^{2}}{4 \kappa}\left(1-e^{-2 \kappa t}\right) \\
& -r t-\sum_{j} \frac{\lambda_{j}}{\kappa} \ln \left[\frac{\mu_{j}-1}{\mu_{j} e^{-\kappa t}-1}\right] .
\end{aligned}
$$

The forward price is given by (see Equation (5) for the definition)

$$
\begin{aligned}
f_{t}=e^{r\left(T_{2}-t\right)} \Psi\left(1, t, T_{2}, X_{t}\right) & \\
=\exp \{ & \theta\left(1-e^{-\kappa \theta t_{2}}\right)+\frac{\sigma^{2}}{4 \kappa}\left(1-e^{-2 \kappa t_{2}}\right)-r t_{2} \\
& \left.\quad-\sum_{j} \frac{\lambda_{j}}{\kappa} \ln \left[\frac{\mu_{j}-1}{\mu_{j} e^{-\kappa t_{2}}-1}\right]+e^{-\kappa \theta t_{2}} X_{t}\right\},
\end{aligned}
$$

where $t_{2}=T_{2}-t$.

We take parameter values from Deng (1999) (see Table A1 in the Appendix) for illustrative purposes. Figure 8 shows forward curves under contango (spot price $=\$ 24.63$ ) and backwardation (spot price $=\$ 120.00$ ). The long-term mean spot price is $\$ 30.00$.

The forward price will converge to a higher quantity than the long-term mean, depending on the parameters for the mean-reverting and jump parts of the model. Observe that the increased volatility from the jumps contributes a signif-
Figure 8. Forward curves under contango and backwardation (affine jump-diffusion).

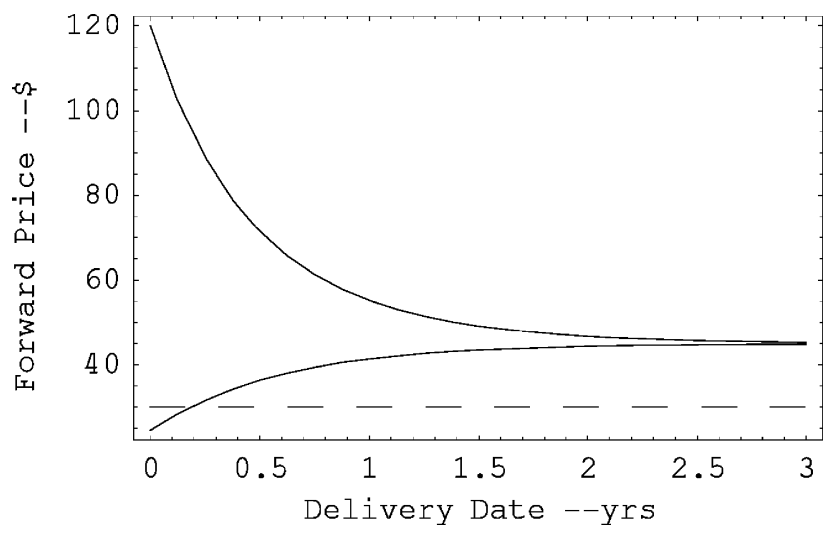

icant amount in forward prices and that they converge well above the long-term mean.

\subsection{Option Pricing}

We calculate option prices under this model by expressing the option price in terms of simpler securities which are functionals of the transform, $\Psi$, and use inversion formulae to derive almost closed-form solutions of the call option price. Let $G_{a, b}(y)$ denote the price of a security that pays $e^{a X_{T}}$ at time $T$ in the event $b . X_{T} \leqslant y$. One can express the call option price expiring at $T_{2}$, in terms of these simpler securities as follows:

$C_{t}\left(k_{T_{2}} \mid f_{t}\right)=G_{1,-1}\left(-\ln k_{T_{2}}\right)-k_{T_{2}} G_{0,-1}\left(-\ln k_{T_{2}}\right)$.

This leads to Proposition 4 (see Figure 9 for the value of the simple call option under an affine jump diffusion).

Proposition 4. The option value in a "callable forward with early notification" after time $T_{1}$ is the price of a simple call option on the forward. The discount to the forward price in a "callable forward" is $e^{r t_{2}}$ times the option price

Figure 9. Value of time- $T_{2}$ call option under an affine jump-diffusion.

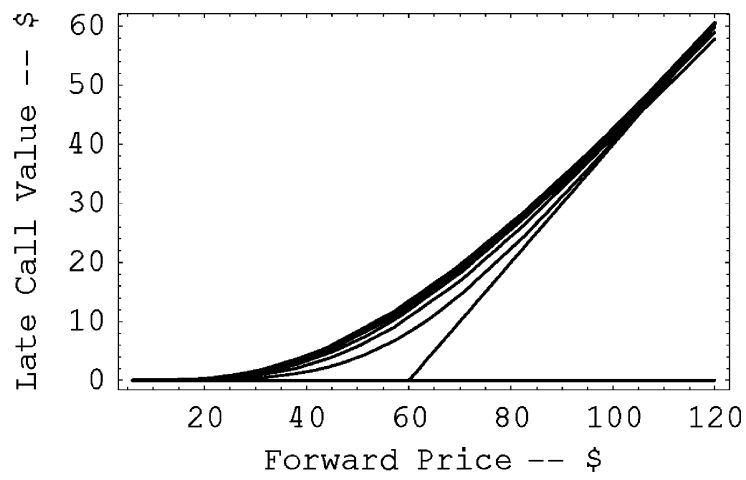


given by

$$
\begin{aligned}
& C\left(k_{T_{2}} \mid f_{t}\right) \\
& =e^{-r t_{2}} f_{t}\left(\frac{1}{2}-\frac{1}{\pi} \int_{0}^{\infty} \frac{\operatorname{Im}\left[\Psi\left(1-i v, t, T_{2}, X_{t}\right) e^{r t_{2}+i v \ln k_{T_{2}}}\right]}{v f_{t}} d v\right) \\
& -e^{-r t_{2}} k_{T_{2}}\left(\frac{1}{2}-\frac{1}{\pi} \int_{0}^{\infty} \frac{\operatorname{Im}\left[\Psi\left(-i v, t, T_{2}, X_{t}\right) e^{r t_{2}+i v \ln k_{T_{2}}}\right]}{v} d v\right),
\end{aligned}
$$

where $f_{t}$ is the forward price at the time of contracting, $k_{T_{2}}$ is the strike price, and $\Psi$ is the transform of the log spot price distribution at $T_{2}$.

The premium on the forward price in a "putable forward" is $e^{r t_{2}}$ times the price of a simple put option given by

$$
\begin{aligned}
& P\left(k_{T_{2}} \mid f_{t}\right) \\
& =e^{-r t_{2}} k_{T_{2}}\left(\frac{1}{2}-\frac{1}{\pi} \int_{0}^{\infty} \frac{\operatorname{Im}\left[\Psi\left(i v, t, T_{2}, X_{t}\right) e^{r t_{2}-i v \ln k_{T_{2}}}\right]}{v} d v\right) \\
& -e^{-r t_{2}} f_{t}\left(\frac{1}{2}-\frac{1}{\pi} \int_{0}^{\infty} \frac{\operatorname{Im}\left[\Psi\left(1+i v, t, T_{2}, X_{t}\right) e^{r t_{2}-i v \ln k_{T_{2}}}\right]}{v f_{t}} d v\right) .
\end{aligned}
$$

Proof. See Appendix.

\subsection{Callable Forward with Early Notification}

As before, at time $T_{1}$ we can determine a unique forward price, $\bar{k}$, as the effective forward price at which the double call option will be exercised at $T_{1}$ (see the discussion in $\S 1.3$ ). The optimal exercise policy will therefore remain the same. We can now proceed in a similar manner and price the double call option before time $T_{1}$ by pricing the three simpler derivatives in (1). In the previous section we had derived the process followed by the forward price and we could price the intermediate call option, $C^{\prime}$, directly using this process. Here, we begin by determining the transform of the forward price at $T_{1}$.

We can write this as

$$
\Phi\left(\gamma, t, T_{1}, X_{t}\right)=E^{Q}\left[e^{-r\left(T_{1}-t\right)} \exp \left\{\gamma Y_{T_{1}}\right\} \mid F_{t}\right]
$$

where $Y_{T_{1}}$ is $\log$ forward price at $T_{1}$ (to be expressed in terms of $X_{t}$ ). Using the formula for $f_{T_{1}}$ in Equation (19), we have

$$
\begin{aligned}
\gamma Y_{T_{1}}=\gamma \ln f_{T_{1}}= & \gamma r\left(T_{2}-T_{1}\right)+\gamma \alpha^{\prime}\left(\left(T_{2}-T_{1}\right), 1\right) \\
& +\gamma \beta^{\prime}\left(\left(T_{2}-T_{1}\right), 1\right) X_{T_{1}}, \\
\Phi\left(\gamma, t, T_{1}, X_{t}\right)=E^{Q} & {\left[e ^ { - r ( T _ { 1 } - t ) } \operatorname { e x p } \left\{\gamma r\left(T_{2}-T_{1}\right)\right.\right.} \\
& +\gamma \alpha^{\prime}\left(\left(T_{2}-T_{1}\right), 1\right) \\
& \left.\left.+\gamma \beta^{\prime}\left(\left(T_{2}-T_{1}\right), 1\right) X_{T_{1}}\right\} \mid F_{t}\right] .
\end{aligned}
$$

The forward price transform at $T_{1}$ can now be written as

$$
\begin{aligned}
& \Phi\left(\gamma, t, T_{1}, X_{t}\right) \\
&=\exp [ \gamma r\left(T_{2}-T_{1}\right)+\gamma \alpha^{\prime}\left(\left(T_{2}-T_{1}\right), 1\right) \\
&+\alpha^{\prime}\left(\left(T_{1}-t\right), \gamma \beta^{\prime}\left(\left(T_{2}-T_{1}\right), 1\right)\right) \\
&\left.+\beta^{\prime}\left(\left(T_{1}-t\right), \gamma \beta^{\prime}\left(\left(T_{2}-T_{1}\right), 1\right)\right) X_{t}\right] .
\end{aligned}
$$

This option can now be priced using Proposition 4. For the compound put option in the double call, we need to work with a joint transform of the forward price at $T_{1}$ and $T_{2}$. To see this, we write the put option as the expected value of the discounted payoff under $Q$ :

$$
\begin{aligned}
& P_{t, T_{1}}^{c o}= E^{Q}\left[e^{-r t_{1}}\left(k_{1}-C_{T_{1}}\left(k_{T_{2}} \mid f_{T_{1}}\right)\right)^{+} \mid F_{t}\right] \\
&= E^{Q}\left[e^{-r t_{1}} k_{1} \Uparrow_{k_{1} \geqslant C_{T_{1}}\left(k_{T_{2}} \mid f_{T_{1}}\right)} \mid F_{t}\right] \\
&-E^{Q}\left[e^{-r t_{1}} E^{Q}\left[e^{-r t_{3}} f_{T_{2}} \Uparrow_{\ln f_{T_{2}} \geqslant \ln k_{T_{2}}} \mid F_{T_{1}}\right]\right. \\
&\left.\cdot \Uparrow_{k_{1} \geqslant C_{T_{1}}\left(k_{T_{2}} \mid f_{T_{1}}\right)} \mid F_{t}\right] \\
&+E^{Q}\left[e^{-r t_{1}} E^{Q}\left[e^{-r t_{3}} k_{T_{2}} \Uparrow_{\ln f_{T_{2}} \geqslant \ln k_{T_{2}}} \mid F_{T_{1}}\right]\right. \\
&\left.\cdot \Uparrow_{k_{1} \geqslant C_{T_{1}}\left(k_{T_{2}} \mid f_{T_{1}}\right)} \mid F_{t}\right],
\end{aligned}
$$

where we use following notation for the indicator function: $\Uparrow_{x \geqslant y}=1$ if $x \geqslant y,=0$ o.w. Now, $k_{1} \geqslant C_{T_{1}}\left(k_{T_{2}} \mid f_{T_{1}}\right)$ is equivalent to $\ln f_{T_{1}} \leqslant \ln \bar{k}$ (see Figure 2). Using the law of iterated expectations we can write the above as

$$
\begin{aligned}
= & k_{1} E^{Q}\left[e^{-r t_{1}} \Uparrow_{\ln f_{T_{1}} \leqslant \ln \bar{k}} \mid F_{t}\right] \\
& -E^{Q}\left[e^{-r t_{2}} \exp \left\{\ln f_{T_{2}}\right\} \Uparrow_{\left.\ln f_{T_{1}} \leqslant \ln \bar{k} \Uparrow \ln f_{T_{2}} \geqslant \ln k_{T_{2}} \mid F_{t}\right]}\right. \\
& +k_{T_{2}} E^{Q}\left[e^{-r t_{2}} \Uparrow_{\left.\ln f_{T_{1}} \leqslant \ln \bar{k} \Uparrow_{\ln f_{T_{2}} \geqslant \ln k_{T_{2}}} \mid F_{t}\right] .}\right.
\end{aligned}
$$

To evaluate these expectations we define the joint transform of the $\log$ forward price at $T_{1}$ and $T_{2}$ :

$$
\begin{aligned}
& \Phi^{\prime}\left(u, v, t, T_{1}, T_{2}, X_{t}\right) \\
& \quad=E^{Q}\left[e^{-r\left(T_{2}-t\right)} \exp \left\{u Y_{T_{1}}+v Y_{T_{2}}\right\} \mid F_{t}\right],
\end{aligned}
$$

where $Y_{T_{1}}=\ln f_{T_{1}}$ and $Y_{T_{2}}=\ln f_{T_{2}}=X_{T_{2}}$, because the forward price will converge to the spot price at delivery. We conjecture the same form as in the single time-point case (this holds for the first two models where the distribution is bivariate normal):

$\Phi^{\prime}\left(u, v, t, T_{1}, T_{2}, X_{t}\right)=\exp \left[\alpha\left(t_{2}, u, v\right)+\beta\left(t_{2}, u, v\right) X_{t}\right]$

Before $T_{1}$, this can be seen as the discounted payoff of a random variable and therefore, $e^{-r t} \Phi_{t}^{\prime}$ will be a martingale under $Q$. Applying Itô's lemma (see Protter 1990 for the complex version) we see that, as before, $\alpha$ and $\beta$ have to follow (17). To determine initial conditions consider $\Phi_{T_{1}}^{\prime}$ :

$$
\begin{aligned}
\Phi_{T_{1}}^{\prime} & =E^{Q}\left[e^{-r\left(T_{2}-T_{1}\right)} \exp \left\{u Y_{T_{1}}+v Y_{T_{2}}\right\} \mid F_{T_{1}}\right] \\
& =\exp \left\{u Y_{T_{1}}\right\} E^{Q}\left[e^{-r\left(T_{2}-T_{1}\right)} \exp \left\{v Y_{T_{2}}\right\} \mid F_{T_{1}}\right]
\end{aligned}
$$

(as $Y_{T_{1}}$ is known at time $T_{1}$ ). 
One can recognize the second term as the transform of the forward price for the one time-point case and substitute from (16). Thus, one can write $\Phi_{T_{1}}^{\prime}$ as

$$
\begin{aligned}
& \Phi^{\prime}\left(u, v, T_{1}, T_{1}, T_{2}, X_{T_{1}}\right) \\
& =\exp \left\{\left(u r t_{3}+u \alpha^{\prime}\left(t_{3}, 1\right)+\alpha^{\prime}\left(t_{3}, v\right)\right)\right. \\
& \left.+\left(u \beta^{\prime}\left(t_{3}, 1\right)+\beta^{\prime}\left(t_{3}, v\right)\right) X_{T_{1}}\right\} .
\end{aligned}
$$

One can now solve for $\Phi_{t}^{\prime}$ by solving (17) for the boundary conditions:

$\alpha\left(t_{3}, u, v\right)=u r t_{3}+u \alpha^{\prime}\left(t_{3}, 1\right)+\alpha^{\prime}\left(t_{3}, v\right)$,

$\beta\left(t_{3}, u, v\right)=u \beta^{\prime}\left(t_{3}, 1\right)+\beta^{\prime}\left(t_{3}, v\right)$.

We can use the joint transform, $\Phi^{\prime}$, to evaluate the expectations in (27) by expressing the compound option value as

$$
\begin{aligned}
P_{t, T_{1}}^{c o}\left(k_{1} \mid f_{t}\right)= & k_{1} G_{0,-1}^{t, T_{1}}(\ln \bar{k})-e^{-r t_{2}} f_{t} \Pi_{1}\left(t, T_{1}, T_{2}\right) \\
& +e^{-r t_{2}} k_{T_{2}} \Pi_{2}\left(t, T_{1}, T_{2}\right),
\end{aligned}
$$

where $k_{1}$ is the strike price for the compound put-on-call, $G^{t, T_{1}}$ is as defined in $\S 3.2$, and $\Pi_{1}$ and $\Pi_{2}$ are defined as

$$
\begin{aligned}
& \Pi_{1}\left(t, T_{1}, T_{2}\right)=\frac{E^{Q}\left[e^{-r t_{2}} \exp \left\{\ln f_{T_{2}}\right\} \Uparrow_{\left.\ln f_{T_{1}} \leqslant \ln \bar{k} \Uparrow \ln f_{T_{2}} \geqslant \ln k_{T_{2}} \mid F_{t}\right]}\right.}{E^{Q}\left[e^{-r t_{2}} \exp \left\{\ln f_{T_{2}}\right\} \mid F_{t}\right]}, \\
& \Pi_{2}\left(t, T_{1}, T_{2}\right)=\frac{E^{Q}\left[e^{-r t_{2}} \Uparrow_{\left.\ln f_{T_{1}} \leqslant \ln \bar{k} \Uparrow \ln f_{T_{2}} \geqslant \ln k_{T_{2}} \mid F_{t}\right]}\right.}{E^{Q}\left[e^{-r t_{2}} \mid F_{t}\right]}
\end{aligned}
$$

It can be easily confirmed that $\Pi_{1}$ and $\Pi_{2} \in[0,1]$, and thus they can be determined by calculating their characteristic functions and inverting according to the method developed in Shepard (1991) (see Bakshi and Madan 1998 for an application to option pricing). To evaluate $\Pi_{1}$ and $\Pi_{2}$ observe that if we treat these as distribution functions, we can express their characteristic functions as

$\Theta_{1}\left(\phi, \varphi, t, T_{1}, T_{2}, X_{t}\right)=\frac{\Phi^{\prime}\left(i \phi, 1+i \varphi, t, T_{1}, T_{2}, X_{t}\right)}{\Phi^{\prime}\left(0,1, t, T_{1}, T_{2}, X_{t}\right)}$,

$\Theta_{2}\left(\phi, \varphi, t, T_{1}, T_{2}, X_{t}\right)=\frac{\Phi^{\prime}\left(i \phi, i \varphi, t, T_{1}, T_{2}, X_{t}\right)}{\Phi^{\prime}\left(0,0, t, T_{1}, T_{2}, X_{t}\right)}$.

This leads to Proposition 5 (see Figure 10 for a plot of the double call option under an affine jump diffusion).

Proposition 5. The discount in the "callable forward with early notification" is equal to $e^{r t_{2}}$ times the price of the double call option at time $t$ (before $T_{1}$ ):

$$
\begin{aligned}
\widehat{C}_{t}\left(k_{T_{1}}, k_{T_{2}} \mid f_{t}\right)= & G_{1,-1}^{\prime}(-\ln \bar{k})-k_{T_{2}} G_{0,-1}^{\prime}(-\ln \bar{k}) \\
& +e^{-r\left(T_{1}-t\right)}\left(G_{1,-1}\left(-\ln k_{T_{2}} \mid f_{T_{1}}=\bar{k}\right)\right. \\
& \left.-k_{T_{2}} G_{0,-1}\left(-\ln k_{T_{2}} \mid f_{T_{1}}=\bar{k}\right)\right) \\
& -\left(k_{1} G_{0,-1}^{t, T_{1}}(\ln \bar{k})-e^{-r t_{2}} f_{t} \Pi_{1}\left(t, T_{1}, T_{2}\right)\right. \\
& \left.\quad+e^{-r t_{2}} k_{T_{2}} \Pi_{2}\left(t, T_{1}, T_{2}\right)\right),
\end{aligned}
$$

Figure 10. Value of the double call option under an affine jump-diffusion.

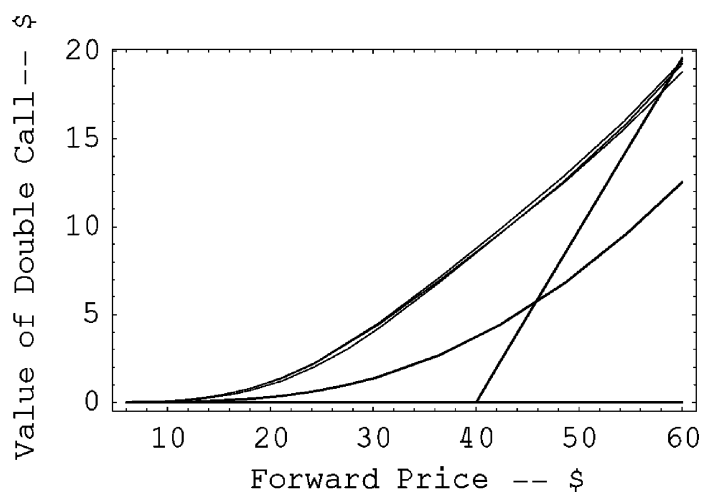

where

$$
\begin{aligned}
& G_{1,-1}^{\prime}(-\ln \bar{k}) \\
& =e^{-r t_{2}} f_{t}\left(\frac{1}{2}-\frac{1}{\pi} \int_{0}^{\infty} \frac{\operatorname{Im}\left[\Phi\left(1-i v, t, T_{1}, X_{t}\right) e^{r t_{1}+i v \ln \bar{k}}\right]}{v f_{t}} d v\right), \\
& G_{0,-1}^{\prime}(-\ln \bar{k}) \\
& =e^{-r t_{2}}\left(\frac{1}{2}-\frac{1}{\pi} \int_{0}^{\infty} \frac{\operatorname{Im}\left[\Phi\left(-i v, t, T_{1}, X_{t}\right) e^{r t_{1}+i v \ln \bar{k}}\right]}{v} d v\right), \\
& G_{1,-1}\left(-\ln k_{T_{2}} \mid f_{T_{1}}=\bar{k}\right) \\
& =e^{-r t_{2}} \bar{k}\left(\frac{1}{2}-\frac{1}{\pi} \int_{0}^{\infty} \frac{\operatorname{Im}\left[\Psi\left(1-i v, t, T_{2}, X_{t}\right) e^{r t_{3}+i v \ln k_{T_{2}}}\right]}{v f_{t}} d v\right), \\
& G_{0,-1}\left(-\ln k_{T_{2}} \mid f_{T_{1}}=\bar{k}\right) \\
& =e^{-r t_{2}}\left(\frac{1}{2}-\frac{1}{\pi} \int_{0}^{\infty} \frac{\operatorname{Im}\left[\Psi\left(-i v, t, T_{2}, X_{t}\right) e^{r t_{3}+i v \ln k_{T_{2}}}\right]}{v} d v\right), \\
& G_{0,-1}^{t, T_{1}}(\ln \bar{k}) \\
& =e^{-r t_{1}}\left(\frac{1}{2}-\frac{1}{\pi} \int_{0}^{\infty} \frac{\operatorname{Im}\left[\Phi\left(-i v, t, T_{1}, X_{t}\right) e^{r t_{1}-i v \ln \bar{k}}\right]}{v} d v\right), \\
& \Pi_{1}\left(t, T_{1}, T_{2}\right) \\
& =\left[\left(\frac{1}{2}-\frac{1}{\pi} \int_{0}^{\infty} \frac{\operatorname{Re}\left[\Theta_{1}\left(0, \phi, t, T_{1}, T_{2}, Y_{T_{1}}\right) e^{-i \phi \ln \bar{k}}\right]}{\phi} d \phi\right)\right. \\
& -\left(-\frac{1}{4}+\frac{1}{2}\left(\frac{1}{2}-\frac{1}{\pi} \int_{0}^{\infty} \frac{\operatorname{Re}\left[\Theta_{1}\left(\phi, 0, t, T_{1}, T_{2}, Y_{T_{1}}\right) e^{-i \phi \ln \bar{k}}\right]}{i \phi} d \phi\right)\right. \\
& \left.+\frac{1}{2}\left(\frac{1}{2}-\frac{1}{\pi} \int_{0}^{\infty} \frac{\operatorname{Re}\left[\Theta_{1}\left(0, \varphi, t, T_{1}, T_{2}, Y_{T_{2}}\right) e^{-i \phi \ln k_{T_{2}}}\right]}{i \varphi} d \varphi\right)\right) \\
& -\left(\frac { 1 } { 2 \pi ^ { 2 } } \int _ { 0 } ^ { \infty } \int _ { 0 } ^ { \infty } \left(\frac{\operatorname{Re}\left[\Theta_{1}\left(\phi, \varphi, t, T_{1}, T_{2}, Y_{T_{1}}, Y_{T_{2}}\right) e^{-i \phi \ln \bar{k}-i \varphi \ln k_{T_{2}}}\right]}{\phi \varphi}\right.\right. \\
& \left.\left.\left.-\frac{\operatorname{Re}\left[\Theta_{1}\left(\phi,-\varphi, t, T_{1}, T_{2}, Y_{T_{1}}, Y_{T_{2}}\right) e^{-i \phi \ln \bar{k}+i \varphi \ln k_{T_{2}}}\right]}{\phi \varphi} d \phi d \varphi\right)\right)\right],
\end{aligned}
$$


and

$$
\begin{aligned}
\Pi_{2}\left(t, T_{1}, T_{2}\right) & {\left[\left(\frac{1}{2}-\frac{1}{\pi} \int_{0}^{\infty} \frac{\operatorname{Re}\left[\Theta_{2}\left(0, \phi, t, T_{1}, T_{2}, Y_{T_{1}}\right) e^{-i \phi \ln \bar{k}}\right]}{\phi} d \phi\right)\right.} \\
- & \left(-\frac{1}{4}+\frac{1}{2}\left(\frac{1}{2}-\frac{1}{\pi} \int_{0}^{\infty} \frac{\operatorname{Re}\left[\Theta_{2}\left(\phi, 0, t, T_{1}, T_{2}, Y_{T_{1}}\right) e^{-i \phi \ln \bar{k}}\right]}{i \phi} d \phi\right)\right. \\
& \left.+\frac{1}{2}\left(\frac{1}{2}-\frac{1}{\pi} \int_{0}^{\infty} \frac{\operatorname{Re}\left[\Theta_{2}\left(0, \varphi, t, T_{1}, T_{2}, Y_{T_{2}}\right) e^{\left.-i \phi \ln k_{T_{2}}\right]}\right.}{i \varphi} d \varphi\right)\right) \\
- & \left(\frac { 1 } { 2 \pi ^ { 2 } } \int _ { 0 } ^ { \infty } \int _ { 0 } ^ { \infty } \left(\frac{\operatorname{Re}\left[\Theta_{2}\left(\phi, \varphi, t, T_{1}, T_{2}, Y_{T_{1}}, Y_{T_{2}}\right) e^{\left.-i \phi \ln \bar{k}-i \varphi \ln k_{T_{2}}\right]}\right.}{\phi \varphi}\right.\right. \\
& \left.\left.\left.-\frac{\operatorname{Re}\left[\Theta_{2}\left(\phi,-\varphi, t, T_{1}, T_{2}, Y_{T_{1}}, Y_{T_{2}}\right) e^{\left.-i \phi \ln \bar{k}+i \varphi \ln k_{T_{2}}\right]}\right.}{\phi \varphi} d \phi d \varphi\right)\right)\right]
\end{aligned}
$$

where $\Psi$ is as defined in (16), $\Phi$ as defined in (25), and $\Theta_{1}$ and $\Theta_{2}$ as defined in (35).

Proof. See Appendix.

As seen in the mean-reverting case, the double call option does not have much time value for long periods before expiration, i.e., its value approaches a steady state with respect to time to expiration.

\section{CONCLUDING REMARKS AND FUTURE RESEARCH}

In a competitive electricity market, financial instruments and derivatives based on underlying commodity contracts will play an important role as means for risk management. Such instruments can also emulate traditional contracts between customers, utilities, and independent power producers aimed at improving the efficiency of resource utilization. The availability of contracts that enable loads to properly hedge their curtailment risk and pricing of such contracts under realistic price models will facilitate load participation in the mitigation of energy and reserve shortages and provide demand response that is needed for a workable competitive market. The California Independent System Operator (CAISO) is currently exploring ways to enlist "Load as a Resource" for creating alternatives to generation reserves in its ancillary service markets.

This paper studies the pricing problem of three efficiency-motivated instruments in the electric power industry. Using increasingly complex price processes, the instruments are priced using forward contracts and optionlike derivatives. The contract prices are first calculated under the canonical GBM model. This is then extended to a mean-reverting spot price diffusion by showing that option prices have the same form under this model with a different variance term. We then introduce jumps in the spot price process and use transform analysis to arrive at almost closed-form formulae under this model.

We observe that mean reversion causes option prices to reach a steady-state value with respect to time to expiration, unlike the GBM case for which option prices approach a constant growth rate. This convergence is because under the mean-reversion assumption, the distribution of the underlying at time of expiration converges to a steady-state distribution. We also observe that volatility from jump behavior can contribute significantly to forward and option prices.

Further research is needed to extend the present model to include another factor, such as regime-switching behavior or a factor that models stochastic volatility in spot prices. An immediate problem in extending the transform analysis technique to these models is that option prices depend on two random variables. While this does not pose a problem for the "callable forward" and the "putable forward" (see Deng 1999 for models with multifactor specifications), pricing the "callable forward with early notification" becomes analytically intractable. In this case, determining the optimal exercise policy will require that both electricity forward price and the volatility level (or regime) be observed at $T_{1}$. This implies that there will not be a unique electricity price at which the later call option price is equal to the payoff from killing it at $T_{1}$. There will instead be a family $\{($ forward price, volatility $)\}$ or $\{$ (forward price, regime) $\}$ as there will be one such price for each level of volatility or regime. Therefore, the problem of pricing the double call option before $T_{1}$ cannot be broken into a simple call option and a compound put-on-call option as before. One would need to directly evaluate the expectation using Monte Carlo simulation or numerically solve the partial differential equation associated with the double call option.

Another extension that can be pursued is to price contracts with multiple exercise points. A triple call option can be priced using Monte Carlo simulation where the almost closed-form solution to the double call provided in this study is used to calculate the payoff at the first strike point.

\section{APPENDIX}

List of parameters and variables

$a_{i}=$ Placeholder for parameters of normal distribution in call option formulae;

$b_{i}=$ Placeholder for parameters of normal distribution in call option formulae;

$B_{t}=$ Standard Brownian motion;

$c=$ Complex parameters in transform;

$d_{i}=$ Placeholder for parameters of normal distribution in call option formulae;

$f_{t}=$ Forward price at time $t$ for delivery at time $T_{2}$;

$F_{t}=$ Information set at time $t$

$k_{1}=$ Strike price of compound put option;

$k_{t}=$ Strike price of exotic option at exercise time $t$

$\bar{k}=$ Effective strike price of early exercise time;

$Q=$ Equivalent martingale measure;

$r=$ Interest rate;

$S_{t}=$ Spot price at time $t$;

$t_{1}=$ Period of time equal to $T_{1}-t$;

$t_{2}=$ Period of time equal to $T_{2}-t$; 
$t_{3}=$ Period of time equal to $T_{2}-T_{1}$;

$T=$ Time of contracting;

$T_{1}=$ Early exercise time;

$T_{2}=$ Expiration time/Delivery date;

$u=$ Complex parameters in transform;

$v=$ Complex parameters in transform;

$V_{t}=$ Shortage cost at time $t$;

$X=$ Natural logarithm of spot price;

$Z_{t}^{i}=$ Compound Poisson process $i$ under measure $Q$;

$\phi=$ Complex parameters in transform;

$\gamma=$ Complex parameters in transform;

$\varphi=$ Complex parameters in transform;

$\kappa=$ Rate of mean reversion;

$\lambda_{I}=$ Arrival intensity of Poisson process;

$\mu=$ Long-run mean price for $X$;

$\mu_{i}=$ Mean size of jumps in Poisson process $i$;

$\mu_{t}=$ Drift parameter of price process;

$\theta=$ Risk-adjusted long run mean price for $X$;

$\sigma=$ Volatility parameter of price process.

We use $t_{3}=T_{2}-T_{1}=0.5$ years in all our examples.

Proof of Proposition 1. We need to evaluate the expression

$C_{t}\left(k_{T_{2}} \mid f_{t}\right)=E^{Q}\left[e^{-r\left(T_{2}-t\right)}\left(f_{T_{2}}-k_{T_{2}}\right)^{+} \mid F_{t}\right]$.

This can be expressed as

$$
\begin{aligned}
& C_{t}\left(k_{T_{2}} \mid f_{t}\right) \\
& =\int_{-\infty}^{\infty} e^{-r\left(T_{2}-t\right)}\left\{\left(f_{t} \exp \left\{-\frac{1}{2} \sigma^{2}\left(T_{2}-t\right)+y\right\}-k_{T_{2}}\right)^{+}\right. \\
& \left.\quad \cdot \frac{1}{\sqrt{2 \pi \sigma^{2}\left(T_{2}-t\right)}} \exp \left(-\frac{y^{2}}{2 \sigma^{2}\left(T_{2}-t\right)}\right)\right\} d y \\
& =\int_{y^{*}}^{\infty} e^{-r\left(T_{2}-t\right)} f_{t} \exp \left\{-\frac{1}{2} \sigma^{2}\left(T_{2}-t\right)+y\right\} \\
& \quad \cdot \frac{1}{\sqrt{2 \pi \sigma^{2}\left(T_{2}-t\right)}} \exp \left(-\frac{y^{2}}{2 \sigma^{2}\left(T_{2}-t\right)}\right) d y \\
& -\int_{y^{*}}^{\infty} e^{-r\left(T_{2}-t\right)} k_{T_{2}} \frac{1}{\sqrt{2 \pi \sigma^{2}\left(T_{2}-t\right)}} \\
& \quad \cdot \exp \left(-\frac{y^{2}}{2 \sigma^{2}\left(T_{2}-t\right)}\right) d y,
\end{aligned}
$$

Table A1. Parameter values for examples in the paper (from Deng 1999).

\begin{tabular}{lr}
\hline Parameter & Value \\
\hline$\kappa$ & 1.70 \\
$\theta$ & 3.40 \\
$\sigma$ & 0.74 \\
$\lambda_{1}$ & 6.08 \\
$\mu_{1}$ & 0.19 \\
$\lambda_{2}$ & 7.00 \\
$\mu_{2}$ & -0.11 \\
\hline
\end{tabular}

where $y^{*}=\ln \left(k_{T_{2}} / f_{t}\right)+\frac{1}{2} \sigma^{2}\left(T_{2}-t\right)$ using the expression for the forward price in (5). To write this expression in terms of the standard normal distribution, we substitute

$d_{1}=\frac{y^{*}-\sigma^{2}\left(T_{2}-t\right)}{\sigma\left(T_{2}-t\right)} \quad$ and $\quad d_{2}=d_{1}-\sigma\left(T_{2}-t\right)$.

This leads to Black's formula in (8). The put option price can be easily calculated using put-call parity to get (9):

$P_{t}\left(k_{T_{2}} \mid f_{t}\right)=C_{t}\left(k_{T_{2}} \mid f_{t}\right)+e^{r t_{2}} k_{T_{2}}-e^{r t_{2}} f_{t}$.

Proof of Proposition 2. We need to show that the option price formulae for the simpler derivatives are as shown. We have

$$
\begin{aligned}
\widehat{C}_{t}\left(k_{T_{1}}, k_{T_{2}} \mid f_{t}\right)= & C_{t, T_{1}}^{\prime}\left(\bar{k} \mid f_{t}\right)+e^{-r\left(T_{1}-t\right)} C_{T_{1}}\left(k_{T_{2}} \mid f_{T_{1}}=\bar{k}\right) \\
& -P_{t, T_{1}}^{c o}\left(e^{-r t_{3}}\left(\bar{k}-k_{T_{1}}\right) \mid f_{t}\right),
\end{aligned}
$$

where the terms are as defined in $\S 1.3$. The first term can be written as

$C_{t, T_{1}}^{\prime}\left(\bar{k} \mid f_{t}\right)=E^{Q}\left[e^{-r t_{1}} e^{-r t_{3}}\left(f_{T_{1}}-\bar{k}\right)^{+} \mid F_{t}\right]$.

Factoring out $e^{-r t_{3}}$ leaves us with the price of a simple call option with strike $\bar{k}$ expiring at $T_{1}$, which can be priced using the formula in Proposition 1 adjusted for the different strike price and expiration date. The second term is a simple call option price, which can be priced directly from Proposition 1 by substituting $\bar{k}$ for the forward price at $T_{1}$. The third term can be written as

$$
\begin{aligned}
P_{t, T_{1}}^{c o}\left(e^{-r t_{3}}\left(\bar{k}-k_{T_{1}}\right) \mid F_{t}\right) & E^{Q}\left[e^{-r t_{1}}\left(k_{1}-C_{T_{1}}\left(k_{T_{2}} \mid f_{T_{1}}\right)\right)^{+} \mid F_{t}\right] \\
= & E^{Q}\left[e^{-r t_{1}} k_{1} \Uparrow_{k_{1} \geqslant C_{T_{1}}\left(k_{T_{2}} \mid f_{T_{1}}\right)} \mid F_{t}\right] \\
& -E^{Q}\left[e^{-r t_{1}} E^{Q}\left[e^{-r t_{3}} f_{T_{2}} \Uparrow_{\ln f_{T_{2}} \geqslant \ln k_{T_{2}}} \mid F_{T_{1}}\right]\right. \\
& \left.\cdot \Uparrow_{k_{1} \geqslant C_{T_{1}}\left(k_{T_{2}} \mid f_{T_{1}}\right)} \mid F_{t}\right] \\
& +E^{Q}\left[e^{-r t_{1}} E^{Q}\left[e^{-r t_{3}} k_{T_{2}} \Uparrow_{\ln f_{T_{2}} \geqslant \ln k_{T_{2}}} \mid F_{T_{1}}\right]\right. \\
& \left.\cdot \Uparrow_{k_{1} \geqslant C_{T_{1}}\left(k_{T_{2}} \mid f_{T_{1}}\right)} \mid F_{t}\right],
\end{aligned}
$$

where $k_{1}=e^{-r t_{3}}\left(\bar{k}-k_{T_{1}}\right)$, and we have used the definition of a simple call option price. It can be noted that $k_{1} \geqslant C_{T_{1}}\left(k_{T_{2}} \mid f_{T_{1}}\right)$ is equivalent to $\ln f_{T_{1}} \leqslant \ln \bar{k}$. Also, because given $f_{t}$ the $\log$ futures price at time $T_{1}$ is a $N\left(\ln f_{t}-\frac{1}{2} \sigma^{2} t_{1}, \sigma^{2} t_{1}\right)$ random variable, all the expectations in the above formula can be expressed in terms of normal or bivariate normal distributions. Consider the second term (after expanding using the law of iterated expectations):

$$
\begin{aligned}
E^{Q}\left[e^{-r t_{1}} e^{-r t_{3}} f_{T_{1}} N\left(\hat{d}_{1}\right) \Uparrow_{k_{1} \geqslant C_{T_{1}}\left(k_{T_{2}} \mid f_{T_{1}}\right)} \mid F_{t}\right] \\
=e^{-r t_{2}} \int_{-\infty}^{\ln \bar{k}} N\left(\hat{d}_{1}\right) \frac{1}{\sqrt{2 \pi} \sigma \sqrt{t_{1}}} e^{x} \\
\cdot \exp \left\{-\frac{1}{2}\left(\frac{x-\ln f_{t}+\frac{1}{2} \sigma^{2} t_{1}}{\sigma \sqrt{t_{1}}}\right)\right\} d x,
\end{aligned}
$$


where we have used the fact that the log futures price is normally distributed at $T_{1}$ and $\hat{d}_{1}$ is $d_{1}$ evaluated with the forward price at $t=T_{1}$.

Making a change of variables,

$y=\frac{x-\ln f_{t}+\frac{1}{2} \sigma^{2} t_{1}}{\sigma \sqrt{t_{1}}}$,

we get

$=e^{-r t_{2}} f_{t} \int_{-\infty}^{-a_{1}} N\left(\hat{d}_{1}\right) \varphi(y) d y$,

where $\varphi(y)$ is the standard normal density function and

$a_{1}=\frac{\ln \left(f_{t} / \bar{k}\right)+\frac{1}{2} \sigma^{2} t_{1}}{\sigma \sqrt{t_{1}}}$.

Now,

$\hat{d}_{1}=\frac{\ln \left(f_{T_{1}} / k_{T_{2}}\right)+\frac{1}{2} \sigma^{2} t_{3}}{\sigma \sqrt{t_{3}}}$,

substituting for $\ln f_{T_{1}}$, we have

$$
\begin{aligned}
\hat{d}_{1} & =\frac{\sigma \sqrt{t_{1}} y+\ln f_{T_{1}}+\frac{1}{2} \sigma^{2} t_{1}-\ln k_{T_{2}}+\frac{1}{2} \sigma^{2} t_{3}}{\sigma \sqrt{t_{3}}} \\
& =\frac{b_{1}-\rho y}{\sqrt{1-\rho^{2}}}
\end{aligned}
$$

where $b_{1}=\frac{\ln \left(f_{t} / k_{T_{2}}\right)+\frac{1}{2} \sigma^{2} t_{2}}{\sigma \sqrt{t_{2}}}$ and $\rho=-\sqrt{\frac{t_{1}}{t_{2}}}$.

Therefore the second term:

$=e^{-r t_{2}} f_{t} N_{2}\left(-a_{1}, b_{1} ; \rho\right)$,

where $N_{2}(a, b ; \rho)$ is the bivariate Normal distribution with correlation $\rho$. One can do similar substitutions for the other terms to get

$$
\begin{aligned}
P_{t, T_{1}}^{c o}\left(k_{1} \mid f_{t}\right)= & e^{-r t_{2}} k_{T_{2}} N_{2}\left(-a_{2}, b_{2} ;-\sqrt{\frac{t_{1}}{t_{2}}}\right) \\
& -e^{-r t_{2}} f_{t} N_{2}\left(-a_{1}, b_{1} ;-\sqrt{\frac{t_{1}}{t_{2}}}\right) \\
& +e^{-r t_{1}} k_{1} N\left(-a_{2}\right),
\end{aligned}
$$

where $a_{1}$ and $b_{1}$ are as above and

$$
a_{2}=a_{1}-\sigma \sqrt{t_{1}} \text { and } b_{2}=b_{1}-\sigma \sqrt{t_{2}} .
$$

Proof of Proposition 3. We begin with the price process in (12) for the log spot price under the risk-neutral measure:

$d X_{t}=\kappa\left(\theta-X_{t}\right) d t+\sigma d B_{t}^{Q}$,

where $X_{t}=\ln S_{t}$.

We will show that given $X_{t}, X_{T}$ will be Gaussian, and its mean and variance are given by

$$
\begin{aligned}
& E^{Q}\left[X_{T} \mid F_{t}\right]=\theta+\left(X_{t}-\theta\right) \exp \{-\kappa(T-t)\}=\mu_{t}^{T}, \\
& \operatorname{Var}^{Q}\left[X_{T} \mid F_{t}\right]=\frac{\sigma^{2}}{2 \kappa}[1-\exp \{-2 \kappa(T-t)\}]=\vartheta_{t}^{2^{T}} .
\end{aligned}
$$

We can then use the GBM formulae in this case with the variance term substituted. We integrate the stochastic differential equation for $X$ using $e^{\kappa s}$ as an integrating factor (see Oksendal 1995):

$$
\int_{t}^{T} e^{\kappa s} d X_{s}=\int_{t}^{T} e^{\kappa s} \kappa \theta d s-\int_{t}^{T} e^{\kappa s} \kappa X_{s} d s+\int_{t}^{T} e^{\kappa s} \sigma d B_{s}^{Q} .
$$

We can eliminate the terms containing $X$ by applying Itô's lemma to $Y_{s}=e^{\kappa s} X_{s}$. The remaining terms can be easily integrated to arrive at the spot price at $T$ :

$$
X_{T}=\theta+\left(X_{t}-\theta\right) \exp \{-\kappa(T-t)\}+\int_{t}^{T} \sigma e^{-\kappa(T-s)} d B_{s}^{Q} .
$$

Because the Itô integral is a Gaussian random variable, $X_{T}$ will be Gaussian with mean (the Itô integral has zero mean):

$E^{Q}\left[X_{T} \mid F_{t}\right]=\theta+\left(X_{t}-\theta\right) \exp \{-\kappa(T-t)\}=\mu_{t}^{T}$.

Also, using Itô isometry (see Oksendal),

$$
\begin{aligned}
\operatorname{Var}^{Q}\left[X_{T} \mid F_{t}\right] & =E\left[\left(\int_{t}^{T} \sigma e^{-\kappa(T-s)} d B_{s}^{Q}\right)^{2}\right] \\
& =\int_{t}^{T} \sigma^{2} e^{-2 \kappa(T-s)} d s,
\end{aligned}
$$

which can be integrated to give

$$
\operatorname{Var}^{Q}\left[X_{T} \mid F_{t}\right]=\frac{\sigma^{2}}{2 \kappa}[1-\exp \{-2 \kappa(T-t)\}]=\vartheta_{t}^{2^{T}} .
$$

As before, the log forward price will be normal under the risk-neutral measure (spot price will be lognormal).

$f_{t}=E^{Q}\left[S_{T} \mid F_{t}\right]=E^{Q}\left[\exp \left\{\ln S_{T}\right\} \mid F_{t}\right]$.

To arrive at an explicit formula, define the (discounted) characteristic of $X_{T}$ as follows:

$\Phi\left(u, t, T, X_{T}\right)=E\left[e^{-r(T-t)} \exp \left\{u X_{T}\right\}\right]$.

One can use the familiar exponential affine for the characteristic function of $X_{T} \sim N\left(\mu, v^{2}\right)$ to get

$$
\Phi\left(u, t, T, X_{T}\right)=\exp \left\{-r(T-t)+u \mu^{T}+\frac{1}{2} u^{2} \vartheta^{2^{T}}\right\} .
$$

The forward price is given by $e^{r}(T-t) \Phi\left(1, t, T, X_{T}\right)$ :

$$
\begin{aligned}
f_{t}= & \exp \left\{\theta+\left(X_{t}-\theta\right)\right\} \exp \{-\kappa(T-t)\} \\
& +\frac{\sigma^{2}}{4 \kappa}[1-\exp \{-2 \kappa(T-t)\}] .
\end{aligned}
$$

The above implies that forward term structure does not converge to the long-term mean of the spot price, but instead to a larger quantity depending on the volatility and rate of mean reversion. 
We can use Itô's lemma to arrive at the process followed by $f$ (this will have zero drift).

$$
\begin{aligned}
d f_{t}=\exp \{-\kappa(T-t)\} \sigma f d B_{t}^{Q} \\
\begin{aligned}
d \ln f_{t}= & -\frac{1}{2} \sigma^{2} \exp \{-2 \kappa(T-t)\} d t \\
& +\exp \{-\kappa(T-t)\} \sigma d B_{t}^{Q}, \\
\therefore \ln f_{T}= & \ln f_{t}-\frac{1}{2} \frac{\sigma^{2}}{2 \kappa}[1-\exp \{-2 \kappa(T-t)\}] \\
& +\int_{t}^{T} \sigma e^{-\kappa(T-s)} d B_{s}^{Q} .
\end{aligned}
\end{aligned}
$$

Forward prices will also be lognormal under this model with different variance than in the GBM case. Therefore, the same formulae will apply with a different variance term.

\section{Affine Jump-Diffusions}

In this section of the Appendix we describe some properties of affine jump-diffusion (AJD) processes that are used in $\S 3$. We restrict ourselves to single-factor AJDs (the general case is considered in Duffie et al. 1998). Consider a more general case of the AJD described in (14):

$d X_{t}=\left(\kappa_{0}+\kappa_{1} X_{t}\right) d t+\sigma d B_{t}^{Q}+\sum_{i=1}^{2} d Z_{t}^{i}$,

where $X_{t}=\ln S_{t}, \kappa_{0}, \kappa_{1}$ and $\sigma$ are parameters, $B_{t}^{Q}$ is standard Brownian motion under the equivalent martingale measure, $Q$, and the $Z^{i}$ s are independent compound Poisson processes under $Q$, with arrival intensities, $\lambda_{i}$, for $i=1,2$. For a detailed description of Poisson processes see Ross (1996). A Poisson process is defined as a counting process possessing the following properties:

1. $N(0)=0$;

2. The process has stationary and independent increments;

3. $P\{N(h)=1\}=\lambda h+o(h)$;

4. $P\{N(h) \geqslant 2\}=o(h)$;

where $N(t)$ represent the number of "events" that have occurred up to time $t$ and $o(h)$ is the asymptotical order symbol, i.e., $f$ is defined as $o(h)$ if

$\lim _{h \rightarrow 0} \frac{f(h)}{h}=0$.

To get a compound Poisson process we assume that each of the Poisson "events" lead to a jump of a random magnitude, $Y_{i}$. We assume that the jump sizes are exponentially distributed. The effect of adding this process to what we had in (11) is that if an event occurs, then neglecting the continuous part, at time $t+h$ the state variable will have a value of $X_{t+h}=X_{t}+Y_{i}$.

All the models analyzed in this study are special cases of (A30). The GBM formulation uses $\kappa_{0}=r-1 / 2 \sigma^{2}, \kappa_{1}=0$. The mean-reverting affine diffusion uses $\kappa_{0}=\kappa \theta, \kappa_{1}=-\kappa$.
Both specifications use constant volatility $\sigma$ and do not model jump behavior (equivalent to setting the arrival intensities to zero). The AJD in $\S 3$ uses the mean-reverting model parameter for the continuous part and the compound Poisson process described above for the jump part.

We first justify the use of the exponential affine form for the Fourier transform of the state variable at time $T_{2}$ (see Equation (16)). As in the proof of Proposition 3, we proceed by eliminating terms having $X_{t}$, by using $e^{-\kappa_{1} s}$ as an integrating factor:

$$
\begin{aligned}
\int_{t}^{T} e^{-\kappa_{1} s} d X_{s}= & \int_{t}^{T} e^{-\kappa_{1} s} \kappa_{0} d s+\int_{t}^{T} e^{-\kappa_{1} s} \kappa_{1} X_{s} d s \\
& +\int_{t}^{T} e^{-\kappa_{1} s} \sigma d B_{s}^{Q}+\sum_{i=1}^{2} \int_{t}^{T} e^{-\kappa_{1} s} d Z_{s}^{i}
\end{aligned}
$$

The remaining terms can be integrated to arrive at an expression for the spot price at $T_{2}$ :

$$
\begin{aligned}
X_{T_{2}}= & -\frac{\kappa_{0}}{\kappa_{1}}+\left(X_{t}+\frac{\kappa_{0}}{\kappa_{1}}\right) \exp \left\{\kappa_{1}\left(T_{2}-t\right)\right\} \\
& +\int_{t}^{T_{2}} \sigma e^{\kappa_{1}\left(T_{2}-s\right)} d B_{s}^{Q}+\sum_{i=1}^{2} \int_{t}^{T_{2}} e^{\kappa_{1}\left(T_{2}-s\right)} d Z_{s}^{i} .
\end{aligned}
$$

Thus, $X_{T_{2}}$ is a sum of random variables $A \sim N\left(\mu_{t}^{T_{2}}, v_{t}^{2^{T_{2}}}\right)$ (mean and variance given in (A17) and (A18)) and $B$ (which equals the last term above), which is a complicated random variable but is a function of time only. Note that in $A$, only the mean is a function of $X_{t}$ and is linear in it. Consider the transform of $X_{T_{2}}$ as defined in (15):

$\Psi\left(v, t, T_{2}, X_{t}\right)=E^{Q}\left[e^{-r\left(T_{2}-t\right)} \exp \left\{v X_{T_{2}}\right\} \mid F_{t}\right]$.

This can be written as

$\Psi\left(v, t, T_{2}, X_{t}\right)=E^{Q}\left[e^{-r\left(T_{2}-t\right)} \exp \{v A+v B\} \mid F_{t}\right]$.

The transform of a normally distributed random variable is given by

$E^{Q}\left[\exp \{v A\} \mid F_{t}\right]=\exp \left\{\mu_{t}^{T_{2}}+\frac{1}{2} v^{2} v_{t}^{2^{T_{2}}}\right\}$,

which is exponentially affine as in (16). The discounting term and the transform of $B$ are both functions of time only and will add to the $\alpha^{\prime}$ term. As $\Psi$ is the discounted expected payoff of a single random variable, $\Psi e^{-r t}$ will be a martingale under $Q$. Applying Itô's lemma to $\Psi e^{-r t}$ (substituting from Equation (16)) we can write its drift as (see Protter 1990)

$$
\begin{aligned}
& \frac{d}{d t} \alpha^{\prime}-r+\kappa_{0} \beta^{\prime}+\frac{1}{2} \sigma \beta^{\prime 2} \\
& \quad+\sum \lambda_{j}\left(\phi_{j}\left(\beta^{\prime}, t\right)-1\right)+\left(\frac{d}{d t} \beta^{\prime}+\kappa_{1} \beta^{\prime}\right) X_{t}=0 .
\end{aligned}
$$

Because this holds for all values of $X_{t}$, we get the ODEs in (17). 
Proof of Proposition 4. Define the characteristic of $G_{a, b}(y)$ as

$$
\begin{aligned}
\widehat{G}_{a, b}(v) & =\int_{\Re} e^{i v y} d G_{a, b}(y) \\
& =\Psi\left(a+i v b, t, T, X_{t}\right) .
\end{aligned}
$$

We now use inversion methods to determine the call formula explicitly using (see Duffie et al. 1998 for an explicit derivation)

$$
\begin{aligned}
G_{a, b}(y) & =\frac{\Psi\left(a, t, T, X_{t}\right)}{2} \\
& -\frac{1}{\pi} \int_{0}^{\infty} \frac{\operatorname{Im}\left[\Psi\left(a+i v b, t, T, X_{t}\right) e^{-i v y}\right]}{v} d v .
\end{aligned}
$$

The call price can therefore be expressed as

$$
\begin{aligned}
C\left(k_{T_{2}} \mid f_{t}\right) & \\
=( & \frac{\Psi\left(1, t, T, X_{t}\right)}{2} \\
& \left.-\frac{1}{\pi} \int_{0}^{\infty} \frac{\operatorname{Im}\left[\Psi\left(1-i v, t, T, X_{t}\right) e^{\left.-i v \ln k_{T_{2}}\right]}\right.}{v} d v\right) \\
& -\left(\frac{\Psi\left(0, t, T, X_{t}\right)}{2}\right. \\
& \left.\quad-\frac{1}{\pi} \int_{0}^{\infty} \frac{\operatorname{Im}\left[\Psi\left(-i v, t, T, X_{t}\right) e^{-i v \ln k_{T_{2}}}\right]}{v} d v\right) .
\end{aligned}
$$

To get the call price in terms of the forward price at $t$, observe that

$\Psi\left(1, t, T, X_{t}\right)=e^{-r t_{3}} f_{t} \quad$ and $\quad \Psi\left(0, t, T, X_{t}\right)=e^{-r t_{3}}$.

Substituting these terms in the option pricing formula, we arrive at (21). We can similarly write the put price as

$P_{t}\left(k_{T_{2}} \mid f_{t}\right)=k_{T_{2}} G_{0,1}\left(\ln k_{T_{2}}\right)-G_{1,1}\left(\ln k_{T_{2}}\right)$.

Proceeding in the manner above, we get (22).

Proof of Proposition 5. Again, we need to show that the option price formulae for the simpler derivatives are as shown. We have

$$
\begin{aligned}
\widehat{C}_{t}\left(k_{T_{1}}, k_{T_{2}} \mid f_{t}\right)= & C_{t, T_{1}}^{\prime}\left(\bar{k} \mid f_{t}\right)+e^{-r t_{1}} C_{T_{1}}\left(k_{T_{2}} \mid f_{T_{1}}=\bar{k}\right) \\
& -P_{t, T_{1}}^{c o}\left(e^{-r t_{3}}\left(\bar{k}-k_{T_{1}}\right) \mid f_{t}\right) .
\end{aligned}
$$

Now the first two terms are a straightforward application of Proposition 4 using the appropriate transform inversion. The third term can also be expressed as (33):

$$
\begin{aligned}
P_{t, T_{1}}^{c o}\left(k_{1} \mid f_{t}\right)= & k_{1} G_{0,-1}^{t, T_{1}}(\ln \bar{k})-e^{-r t_{2}} f_{t} \Pi_{1}\left(t, T_{1}, T_{2}\right) \\
& +e^{-r t_{2}} k_{T_{2}} \Pi_{2}\left(t, T_{1}, T_{2}\right) .
\end{aligned}
$$

The first term can be evaluated using an application of Proposition 4. To evaluate $\Pi_{1}$ and $\Pi_{2}$ we use the characteristic functions in (35). Now, for a bivariate distribution,
$F(a, b)$, of two random variables $S$ and $P$, we can express $F(S \leqslant a, P \geqslant b)$ as

$F(S \leqslant a, P \geqslant b)=F(S \leqslant a)-F(S \leqslant a, P \leqslant b)$.

If the characteristic function, $\Theta(\phi, \varphi ; S, P)$, of $F$ is known we can use the method in Shepard (1991) (see Bakshi and Madan 1998 for an application to option pricing) to invert $\Theta(\phi, \varphi ; S, P)$ to get the desired probabilities given by

$$
\begin{gathered}
F(S \leqslant a)=\frac{1}{2}-\frac{1}{\pi} \int_{0}^{\infty} \operatorname{Re}\left[\frac{\Theta(\phi, 0 ; S) e^{-i \phi a}}{i \phi}\right] d \phi, \\
F(S \leqslant a, P \leqslant b) \\
=-\frac{1}{4}+\frac{1}{2} F(S \leqslant a)+\frac{1}{2} F(P \leqslant b) \\
-\left(\frac { 1 } { 2 \pi ^ { 2 } } \int _ { 0 } ^ { \infty } \int _ { 0 } ^ { \infty } \left\{\operatorname{Re}\left[\frac{\Theta(\phi, \varphi ; S, P) e^{-i \phi a-i \varphi b}}{\phi \varphi}\right]\right.\right. \\
\left.\left.-\operatorname{Re}\left[\frac{\Theta(\phi,-\varphi) e^{-i \phi a+i \varphi b}}{\phi \varphi}\right]\right\} d \phi d \varphi\right) .
\end{gathered}
$$

The compound option formula can be derived by applying the above results to $\Pi_{1}$ and $\Pi_{2}$.

\section{ACKNOWLEDGMENTS}

The authors would like to thank the editors and four anonymous referees for many useful comments and suggestions for improving the presentation of this paper. The first author thanks Shijie Deng for many helpful discussions and Darrell Duffie for comments, which helped guide the research at an early stage. This research was supported by the Power Systems Engineering Research Center (Pserc) and by the University of California Energy Institute.

\section{REFERENCES}

Amin, K., V. Ng, S. C. Pirrong. 1995. Valuing energy derivatives. Managing Energy Price Risk. Risk Publications, London, U.K., 57-70.

Bakshi, G., D. Madan. 1998. Spanning and derivative-security valuation. Working paper, Department of Finance, University of Maryland, College Park, MD.

Bates, D. S. 1991. The crash of '87: Was it expected? The evidence from options markets. J. Finance 46 1009-1044.

Birge, J. R., S. G. Kou. 1999. Pricing of electricity options under a jump diffusion model. Working paper, McCormick School of Engineering and Applied Sciences, Northwestern University, Evanston, IL.

Bjerksund, P., S. Ekern. 1995. Contingent claims evaluation of mean-reverting cash flows in shipping. L. Trigeorgis, ed. Real Options in Capital Investment: Models, Strategies, and Applications. Preager, Westport, CT.

Black, F. 1976. The pricing of commodity contracts. J. Financial Econom. 3 167-179.

Cater, J. C. 1995. Valuing options for electric power resources. Electricity J. 20 43-49.

Chao, H.-P., R. Wilson. 1987. Priority service: Pricing, investment, and market organization. Amer. Econom. Rev. 77 899-916. 
Cox, J., M. Rubinstein. 1985. Options Markets. Prentice Hall, Englewood Cliffs, NJ.

Deng, S. 1999. Stochastic models of energy commodity prices and their applications: Mean-reversion with jumps and spikes. 4th Annual Research Conference on Electricity Industry Restructuring. University of California, Berkeley, CA.

B. Johnson, A. Sogomonian. 1998. Exotic electricity options and the valuation of electricity generation and transmission assets. Proc. Chicago Risk Management Conference (May), Chicago, IL.

Duffie, D. 1996. Dynamic Asset Pricing Theory. Princeton University Press, Princeton, NJ.

_, R. Kan. 1996. A yield-factor model of interest rates. Math. Finance 6 379-406.

_ J. Jan, K. Singleton. 1998. Transform analysis and option pricing for affine jump-diffusions. Preliminary draft, Graduate School of Business, Stanford University, Stanford, CA.

Gedra, T. W. 1991. Optional forward contracts for electric power service contracts. Ph.D. dissertation, Department of Electrical Engineering and Computer Science, University of California, Berkeley, CA.

$\ldots$, P. Varaiya. 1993. Markets and pricing for interruptible electric power. IEEE Trans. Power Sys. 8 122-128.

Geske, R. 1979. The valuation of compound options. J. Financial Econom. 7 63-81.

Gibson, R., E. S. Schwartz. 1990. Stochastic convenience yield and the pricing of oil contingent claims. J. Finance 45 959-976.

Harrison, M., D. Kreps. 1979. Martingales and arbitrage in multiperiod securities markets. J. Econom. Theory 20 381-408.

Heath, D., R. A. Jarrow, A. J. Morton. 1992. Bond pricing and the term structure of interest rates: A new methodology of contingent claims pricing. Econometrica 60 77-105.

Heston, S. L. 1993. A closed-form solution for options with stochastic volatility with applications to bond and currency options. Rev. Financial Stud. 6 327-343.

Hilliard, J. E., J. Reis. 1998. Valuation of commodity futures and options under stochastic convenience yields, interest rates and jump diffusions in the spot. J. Financial Quant. Anal. 33 61-86.

Hull, J. C. 2000. Options, Futures and Other Derivatives, 4th ed. Prentice Hall, Englewood Cliffs, NJ.
Kaminsky, V. 1997. The challenge of pricing and risk managing electricity derivatives. The US Power Market. Risk Publications, London, U.K., 149-171.

Merton, R. C. 1976. Option pricing when underlying stock returns are discontinuous. J. Financial Econom. 3 125-144.

Miltersen, K. R., E. S. Schwartz. 1998. Pricing of options on commodity futures with stochastic term structure of convenience yields and interest rates. J. Financial Quant. Anal. 33 33-59.

Oksendal, B. K. 1995. Stochastic Differential Equations: An Introduction with Applications, 4th ed. Springer, New York.

Oren, S. S. 1999. Combining financial double call options with real options for early curtailment of electricity service. Proc. 32nd Hawaii Internat. System Sci. Conf. (January), Hawaii.

Pilipovic, D. 1998. Energy Risk: Valuing and Managing Energy Derivatives. McGraw-Hill, New York.

Protter, P. 1990. Stochastic Integration and Differential Equations. Springer-Verlag, New York.

Ross, S. A. 1995. Hedging long run commitments: Exercise in incomplete market pricing. Preliminary draft.

Ross, S. M. 1996. Stochastic Processes, 2nd ed. John Wiley and Sons, New York.

Schwartz, E. S. 1997. The stochastic behavior of commodity prices: Implications for valuation and hedging. J. Finance $\mathbf{5 2}$ 923-973.

_ J. E. Smith. 2000. Short-term variations and longterm dynamics in commodity prices. Management Sci. 46 893-911.

Shepard, N. 1991. From characteristic function to a distribution function: A simple framework for theory. Econometric Theory 7 519-529.

Stein, E. M., J. C. Stein. 1991. Stock price distributions with stochastic volatility: An analytical approach. Rev. Financial Stud. 4 727-752.

Strauss, T. P., S. S. Oren. 1993. Priority pricing of interruptible electric power with an early notification option. Energy J. 14 $175-195$.

Thompson, A. C. 1995. Valuation of path-dependent contingent claims with multiple exercise decisions over time: The case of take-or-pay. J. Financial Quant. Anal. 30 271-293. 